California State University, Monterey Bay

Digital Commons@ @ CSUMB

Summer 2012

\title{
Assessing Pesticide Reduction in Constructed Wetlands Using a Tanks-in-Series Model Within a Bayesian Framework
}

Pamela Krone-Davis

California State University, Monterey Bay, pkrone-davis@csumb.edu

Follow this and additional works at: https://digitalcommons.csumb.edu/sns_theses

\section{Recommended Citation}

Krone-Davis, Pamela, "Assessing Pesticide Reduction in Constructed Wetlands Using a Tanks-in-Series Model Within a Bayesian Framework" (2012). SNS Master's Theses. 7.

https://digitalcommons.csumb.edu/sns_theses/7

This Master's Thesis (Open Access) is brought to you for free and open access by the School of Natural Sciences at Digital Commons @ CSUMB. It has been accepted for inclusion in SNS Master's Theses by an authorized administrator of Digital Commons @ CSUMB. For more information, please contact digitalcommons@csumb.edu. 


\title{
ASSESSING PESTICIDE REDUCTION IN CONSTRUCTED WETLANDS USING A TANKS-IN-SERIES MODEL WITHIN A BAYESIAN FRAMEWORK
}

\author{
A Thesis \\ Presented to the \\ Faculty of the \\ Division of Science and Environmental Policy \\ California State University Monterey Bay \\ In Partial Fulfillment \\ of the Requirements for the Degree \\ Master of Science \\ in \\ Coastal and Watershed Science and Policy
}

by

Pamela Krone-Davis

Summer 2012 


\section{CALIFORNIA STATE UNIVERSITY MONTEREY BAY}

The Undersigned Faculty Committee Approves the Thesis of Pamela Krone-Davis:

\section{ASSESSING PESTICIDE REDUCTION IN CONSTRUCTED WETLANDS USING A TANKS-IN-SERIES MODEL WITHIN A BAYESIAN \\ FRAMEWORK}

Fred Watson, Committee Chair

Division of Science and Environmental Policy, CSUMB

Marc LosHuertos

Division of Science and Environmental Policy, CSUMB

Keith Starner

California Department of Pesticide Regulation, Sacramento, Ca

Marsha Moroh, Dean

College of Science, Media Arts, and Technology, CSUMB 
Copyright (C) 2012

All Rights Reserved 
"We do not inherit the earth from our ancestors; we borrow it from our children." Chief Seattle 


\begin{abstract}
Assessing Pesticide Reduction in Constructed Wetlands using

a Tanks-in-Series Model within a Bayesian Framework

by

Pamela Krone-Davis

Master of Science in Coastal and Watershed Science and

Policy

California State University Monterey Bay, 2012
\end{abstract}

Frequent pesticide detection at toxic levels to test organisms in California's Central Coast waterbodies has motivated regulators, resource agencies and end-users to investigate and adopt management practices and technologies to diminish agricultural chemicals entering receiving waters. Treatment wetlands are a technology of special interest because of their ability to simultaneously treat multiple pollutants commonly found in agricultural and urban runoff including nitrate, suspended sediment and pesticides. We sought evidence for transformation of three highly water soluble pesticides (diazinon, methomyl and acephate) in a full-scale constructed treatment wetland located at the base of the Salinas Valley. We pumped water into the wetland from a slough containing agricultural runoff. The pumping rate was set to achieve a fourday mean residence time, and outlet samples were collected four days after inlet samples. We developed a dynamic tanks-in-series model and fit it to pesticide concentration data from the wetland, using parameters for number of tanks in series, mean hydraulic residence time, pesticide decay, and two parameters for inlet concentrations outside of the sampling period. We used a Bayesian analytical approach to determine the $95 \%$ credible intervals (CI) and most likely values for the five model parameters, and developed inference for pesticide decay based on the CI for the decay rate parameter. The CIs for the three pesticide decay parameters were positive and did not span zero, supporting the postulate that the wetland removed these pesticides to some extent. CIs for first-order decay rates were 0.097-0.289 day $^{-1}$ for diazinon, 0.068-0.232 day $^{-1}$ for methomyl, and 0.068-0.246 day ${ }^{-1}$ for acephate. These intervals can be used in conjunction with simple decay models to optimize the design of wetlands and to estimate size requirements. 


\section{TABLE OF CONTENTS}

PAGE

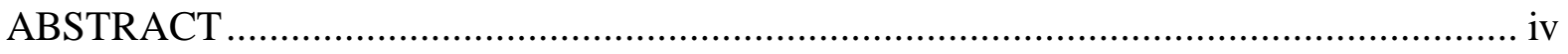

ACKNOWLEDGEMENTS ............................................................................. vii

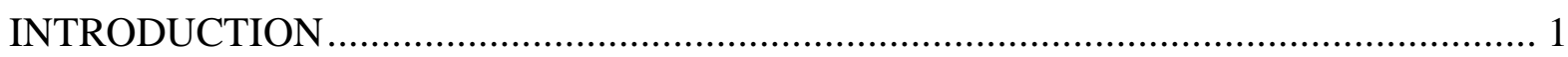

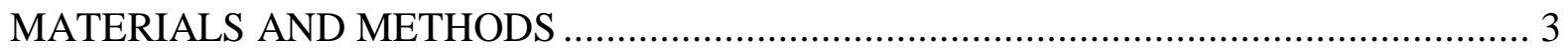

Wetland Site and Watershed ....................................................... 3

Pesticide Sampling and Analysis....................................................... 4

Hydrologic Modeling of Residence Time and First Order

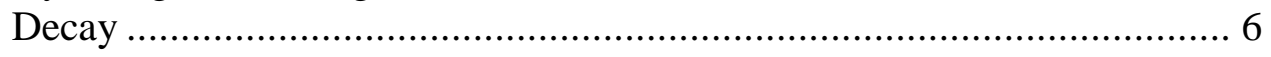

Bayesian Analysis with Markov Chain Metropolis Sampler .................. 8

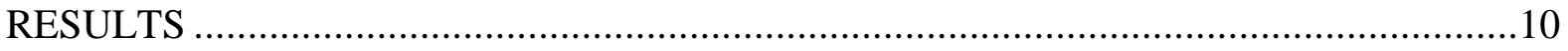

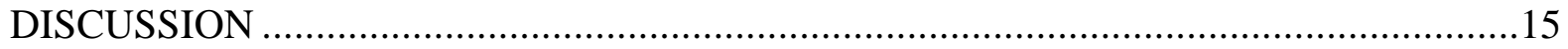

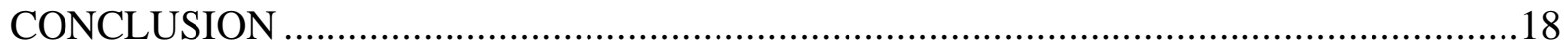

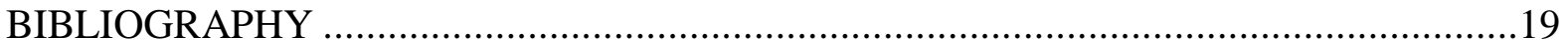

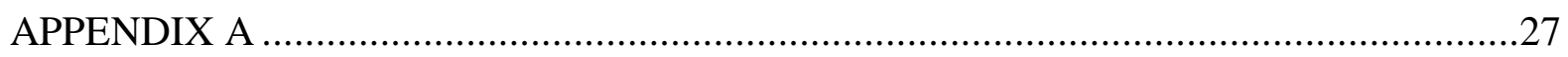

PESTICIDE SAMPLING RESULTS ................................................27

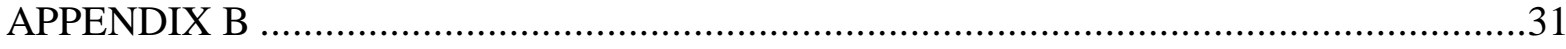

BAYESIAN RESULTS FOR MODEL PARAMETERS ...........................31

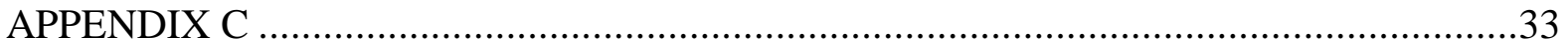

TRACER TEST AND DETERMINATION OF PRIORS FOR

HYDRAULIC PARAMETERS ..........................................................33

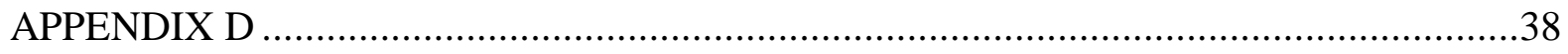

REGULATORY BACKGROUND .................................................. 38

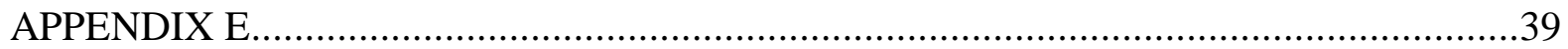

TANKS IN SERIES CONCEPTUAL MATH........................................39 


\section{ACKNOWLEDGEMENTS}

This project has resulted from the dedication and commitment of many people. Dr. Fred Watson strategized the approach to the experimental design, modeling and statistical analysis as well as working closely with me throughout the project. Dr. Marc Los Huertos provided helpful insight and critique throughout the project as well as allowing the use of laboratory and field equipment. Keith Starner initiated the project, secured DPR funding and furthered my understanding of the regulatory side of pesticide control. Special thanks to Miles Daniels for participating in the Tracer Test and the development of the Bayesian model, and to Erin Stanfield and Emily Paddock for helping with the Ion Chromatograph. Thanks to Jennifer Christy, the UROC student, who helped so diligently during the summer of 2010 and to Matt Subia for organizing UROC students. Thanks to Evan Delay and Mitch Vernon for volunteering your time to work on the tracer test and analysis.

Thank-you to other faculty members who were important to my learning through the CWSP program: Dr. Doug Smith for stimulating my interest and excitement, Dr. Suzy Worcester for being my first advisor and helping me establish a direction, as well as many others. I want to thank fellow students and associates who inspired me through the program and made doing the work stimulating and fun, including everyone, with special thanks to Violetta Pristel, Carolyn Rosevelt, Arnett Young, Sandy Clifton, Emily Paddock, Bart Kowalski, Jake Smith, Ty Brandt, Colin Nicol, William Perry, AJ Purdy and Alberto Guzman.

My family has been incredibly supportive of me throughout my master program work. Thanks to my parents for always having confidence. Thanks to my husband who did the midnight run to keep gas in the wetland pump. Thanks to my daughter for leading the way by starting her master's program at the same time and completing her degree much sooner. Thanks to my son, who keeps me thinking about what is important in life. Thank-you to my brothers for not letting me get too carried away in self importance. 


\section{INTRODUCTION}

Agricultural production makes the largest economic contribution to Monterey County of all industries, grossing over $\$ 4$ billion in both $2009 \& 2010$, with nearly $60 \%$ of the nation's lettuce and artichokes and $85 \%$ of the strawberries grown in Monterey County (MCAC 2011, MPCC 2012). This agricultural productivity is achieved through a long growing period, fertile soils, innovative management practices, and advanced technologies including pest control methods. Pest control is accomplished through mechanical, biological and chemical methods, with nearly 4 million $\mathrm{kg}$ of pesticides applied in Monterey County in 2010 of nearly 300 different active ingredients (CADPR 2012, CADPR PUR 2012). Pesticide use will likely increase as global warming changes the developmental patterns and eating habits of insects and increases the severity of invasive species' impacts, and as human population growth requires greater agricultural production (Tillman et al. 2001, Trumble and Butler 2009)

Although rarely applied directly to water, pesticides may be carried to public waters by runoff, overspray and atmospheric deposition, and can originate from either agricultural and/or urban sources (Larkin and Tjeerdema 2000, Schulz 2004). Pesticide application rates are spatially correlated with concentrations found in streams in the central coast of California (Hunt et al. 2006). A summary of California Department of Pesticide Regulation (DPR) monitoring results between 2008-2010 of six California counties found the organophosphate (OP) and carbamate pesticides detection frequency in waters ranged from $4 \%$ to $72 \%$, with the highest frequency reported for diazinon (Starner 2012). Monitoring programs by the California Department of Pesticide Regulation and the Cooperative Monitoring Program show frequent pesticide detection in Central Coast waters (CCWQPI 2008, CCWQPI 2010, CADPR 2011). The Central Coast's Cooperative Monitoring Program evaluated organophosphate (OP) compounds in water in 2006 and 2007 in Monterey and San Luis Obispo Counties, detecting OP pesticides at all 23 sites monitored (CCWQPI 2008). Both chlorpyrifos and diazinon were detected at concentrations above the 303(d) listing criteria $(0.025 \mathrm{ppb}$ and $0.16 \mathrm{ppb}$ respectively) at 15 and 12 sites respectively (CCWQPI 2008). The DPR reported 
monitoring results from 33 sites for diazinon in Salinas Valley between 2005-2008 for a total of 244 samples, finding that $70 \%$ of samples exceeded the $0.10 \mathrm{ppb}$ target concentration (Zhang and Starner 2011). This target concentration was developed by the California State Water Resources Control Board for the San Joaquin and Sacramento Watershed and also represents the Criterion Continuous Concentration established for the Salinas watershed (CSWRCB 2008, CCRWQCB 2010).

Management practices under investigation worldwide to reduce pesticide entry into streams include altering the types of pesticides used, changing irrigation practices, changing application processes, and treating runoff before it enters public water ways by means such as no-spray zones, vegetated buffer strips, riparian vegetation, enzyme addition, and vegetated treatment systems (Schulz 2004, Reichenberger et al. 2007, Anderson et al. 2010). A number of studies have demonstrated that pesticides with high adherence coefficients and hydrophobicity, such as pyrethroids, can be reduced or removed from water passing through constructed wetlands or vegetated ditches, due primarily to adsorption to particles that settle and to plant surfaces (Bennett et al. 2005, Budd et al. 2009). More difficult to ascertain is the effectiveness of vegetated treatment systems and wetlands in removing highly water soluble pesticides (Reichenberger et al. 2007), such as those considered in this study.

The objective of our study was to establish a $95 \%$ credible interval for the decay rates of three water soluble pesticides (diazinon, methomyl, and acephate) through modeling wetland hydrology in order to distinguish decay from mixing. We postulated that a free water surface treatment wetland would reduce the concentrations of pesticides through decay processes such as hydrolysis, photolysis, and biological degradation. Specifically, we modeled a parameter representing the rate of decay of pesticides between the inlet and the outlet and estimated credible intervals for this parameter using Bayesian analysis. We inferred support for the postulate from the degree to which the credible intervals included zero. 


\section{MATERIALS AND METHODS}

\section{WETLAND SITE AND WATERSHED}

The wetland is located on a 1.2 hectare parcel at the confluence of the Tembladero Slough and Old Salinas River Channel at the base of the Salinas Valley, CA, USA at Latitude (36.7718) and Longitude (-121.788). Ambient year round temperature varies between $50^{\circ} \mathrm{F}$ and $75^{\circ} \mathrm{F}$ is and morning fog is common (http://www.nws.noaa.gov). The contributing watershed covers 39,000 hectares comprised of 36\% agricultural and 12\% urban land (CCRWQCB 2011). In 2010 a total of $17,400 \mathrm{~kg}$ of diazinon were applied to the watershed from farm operations (DPR 2012). Urban use of diazinon is no longer permitted and detections in urban areas have diminished since their final phase out in 2004 (Zhang and Starner 2011).

The wetland channel morphology formed a long sinuous pattern 280 meters in length by 6.5 meters wide and 0.3 meters deep (Figure 1). It was designed to have a high length to width ratio (43:1) intended to maximize plug-flow and minimize shortcircuiting (Harris et al. 2007). Bulrushes and sedges were established along the channel edges and Tule (Schoenoplectus californicus) on berms across the channel at periodic intervals, covering about $30 \%$ of the channel. Floating Duckweed (Lemna minor) and algae (primarily Ulva intestinales ) predominated the open water between the sedge covered berms. Inlet water was pumped from the upper $10 \mathrm{~cm}$. of the water column of the Tembladero Slough, with a float attached to the inlet pipe to maintain its position on the surface. Floating the inlet allowed us to minimize entrainment of sea water into the wetland due to the salinity gradient in the slough. Water was pumped at a rate of $1.325 \mathrm{~L} \mathrm{~s}^{-1}$ to achieve a hydraulic retention time of four days. Because water flows at different rates to the outlet over a residence time distribution (RTD), the 4 day interval matched the peak of the RTD, as established by a bromide tracer study conducted prior to pesticide sampling. 


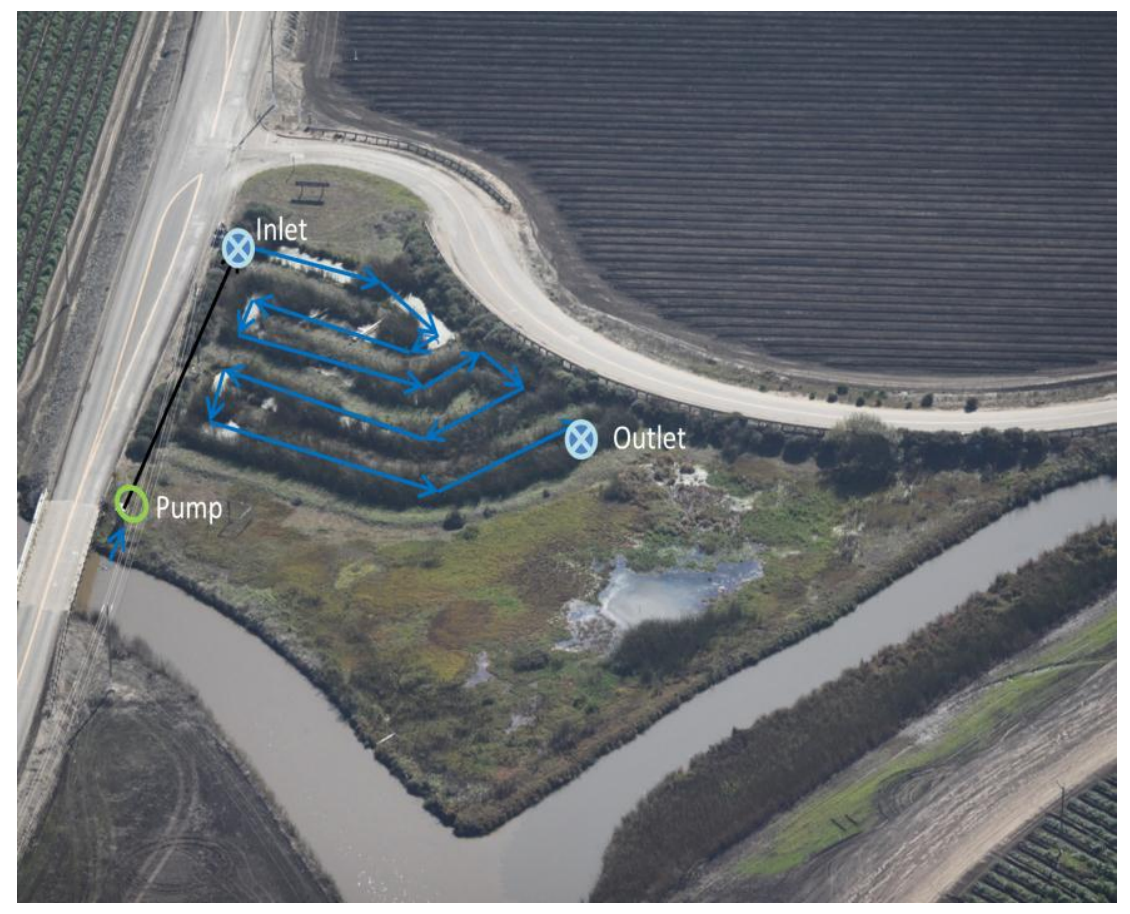

Figure 1. Molera Experimental Wetland. This aerial photograph shows the sinuous wetland channel winding back and forth. (Photo: E.Delay \& J.Hatfield, 2010)

\section{Pesticide SAmpling AND ANAlysis}

During the summer of 2009, DPR collected pilot samples on 13 sample dates in Tembladero Slough near the pumped inlet of the wetland to determine which pesticides to investigate for wetland mitigation and to establish the timing of 2010 sampling events (Starner 2010). The 2010 sampling schedule coincided with times when pesticides of interest were likely to be detected in the Slough. From April 28 through July 29, 2009, diazinon samples consistently ranged between 0.08 and $0.17 \mathrm{ppb}$, with a drop to between 0.03 and 0.09 between 8/31/09 and 9/16/09 (Table 1). Methomyl showed no clear detection pattern and acephate was consistently detected in samples taken between 7/27/09 and 9/1/09. 
Table 1. Pesticide sampling concentrations (ppb) from 2009 at Tembladero Slough near the Molera Wetland intake. When two samples were taken on the same date, the concentrations were averaged. In these cases, there was never a detected and non-detected concentration on the same day.

\begin{tabular}{lccc}
\hline Date & Diazinon $(\mathrm{ppb})$ & Methomyl $(\mathrm{ppb})$ & Acephate $(\mathrm{ppb})$ \\
\hline \hline $4 / 28 / 2009$ & 0.101 & ND & ND \\
$6 / 1 / 2009$ & 0.080 & 1.530 & 0.391 \\
$6 / 2 / 2009$ & 0.114 & 0.778 & ND \\
$6 / 18 / 2009$ & 0.134 & 0.080 & ND \\
$7 / 27 / 2009$ & 0.090 & 0.917 & 0.615 \\
$7 / 28 / 2009$ & 0.083 & 0.452 & 0.502 \\
$7 / 29 / 2009$ & 0.173 & 0.360 & 0.265 \\
$8 / 31 / 2009$ & 0.029 & 0.173 & 1.690 \\
$9 / 1 / 2009$ & 0.043 & 0.275 & 0.589 \\
$9 / 2 / 2009$ & 0.028 & 0.118 & ND \\
$9 / 14 / 2009$ & 0.095 & 0.642 & ND \\
$9 / 15 / 2009$ & 0.064 & 0.362 & ND \\
$9 / 16 / 2009$ & 0.059 & 0.197 & ND \\
\hline
\end{tabular}

Pesticide sampling at the Molera Wetland took place between July 5 and July 11, 2010. A total of 18 samples were collected consisting of two samples taken at the inlet on Day 1, four samples on Day 2 and three samples on Day 3, spaced throughout daylight hours. Outlet samples were taken four days later on Day 4, Day 5 and Day 6, at matching times to inlet samples (Table A1). Pesticide samples were also taken from Tembladero Slough water near the wetland inlet six times to allow for comparison of inlet and surface water concentrations. Water quality measurements of dissolved oxygen $(\mathrm{mg} / \mathrm{L})$, water temperature $\left({ }^{\circ} \mathrm{C}\right), \mathrm{pH}$, specific conductivity $(\mu \mathrm{S} / \mathrm{cm})$, total dissolved solids $(\mathrm{g} / \mathrm{L})$, and turbidity (NTU) were taken continuously during the sampling period by three Hydrolab Sondes DS5X (Hach, Loveland, CO) immersed in the wetland. One was placed near the wetland inlet, a second at the wetland midpoint and a third at the three-quarter point. In addition, we collected sample water at the wetland inlet and outlet to analyze chloride, nitrate, nitrite, bromide, fluoride and sulfate concentrations by ionic chromatography with a Dionex ICS 2000 (Thermo Scientific, Sunnyvale, CA) using modified EPA method 300.0 (Pfaff 1993). Quality Assurance Procedures included comparisons with known concentrations, duplicate field and lab samples, matrix spike samples, and analytical blanks. Pesticide sampling and handling, was conducted by DPR personnel and 
extraction and analysis by California Department of Food and Agriculture personnel following standard DPR protocol (CADPR 2006, CADPR 2007, CADPR 2008).

\section{Hydrologic MOdeling OF ReSIDENCE TIME ANd First ORdER DECAY}

We used a tanks-in-series model (Levenspiel 1998) to simulate wetland hydrology, and Bayesian analysis to estimate credible intervals for model parameters (Figure 6). When deciding on this statistical approach, we contemplated other methods such as a paired t-test, regression, and AIC model comparison. The need to minimize our sample size due to the high cost of pesticide sampling influenced our choice. Simple statistical approaches such as a paired t-test or regression would not have been informative due to the small sample size. To determine the required sampling interval with 18 samples, we used AIC model comparison of a null (no-decay) model with a first order decay model under different residence times. We used an advection dispersion model assuming 2, 3, 4 and 5 day residence times and found that the decay model did not outperform the null model until a 4 day residence time was modeled (Watson and Daniels 2010 unpublished data). For statistical analysis of the 2010 sampling period that was the focus of the present study, due to the dynamic nature of pesticide concentration observed (non steady state, non-stationary distributions), we decided that an approach based around hydraulic simulation (within a Bayesian inferential framework) better suited the analysis.

Our hydraulic model used the standard tanks-in-series (TIS) approach common in chemical engineering. TIS is an analytic formulation that assumes flow through a wetland behaves in the same way as flow through a series of fully mixed tanks (Levenspiel 1998, Clark 2009). This leads to a gamma distribution of residence times based on two parameters, the mean residence time $(\bar{\tau})$ and the number of tanks in series $(N)$. The TIS model can be mathematically coupled with equations for the instantaneous rate of chemical decay to lead to a corresponding steady state prediction of the net decay through an entire wetland (Kadlec and Wallace 2009). Thus, a stand alone TIS model can be used for wetland design under steady state conditions.

Under a tanks-in-series conceptualization, the residence time distribution (RTD) follows a gamma distribution (Levenspiel 1998, Clark 2009): 


$$
g\left(\tau ; k_{R}, \theta_{R}\right)=\operatorname{Gamma}\left(\tau ; k_{R}, \theta_{R}\right)=\frac{N}{\bar{\tau}\lceil(N)}\left(\frac{N \tau}{\bar{\tau}}\right)^{N-1} \exp \left(-\frac{N \tau}{\bar{\tau}}\right), k_{R}=N, \theta_{R}=\frac{\bar{\tau}}{N}
$$

where $\operatorname{Gamma}\left(\tau ; k_{R}, \theta_{R}\right)$ is a gamma distribution of residence times, $\tau(\mathrm{hr})$, with shape and scale parameters $k_{R}$ and $\theta_{R}$. Under first-order decay, the concentration $C_{\text {out }, p}$ of an arbitrary parcel $(p)$ of water relative to that parcel's inlet concentration inlet concentration $C_{i n, p}$ at time $\tau=0$ is described by an exponential function with decay parameter $k$

$$
\frac{C_{\text {out }, p}}{C_{\text {in }, p}}=f(\tau)=\exp (-k \tau)
$$

Under steady state, all parcels have time-invariant inlet concentration $C_{i n, p}=C_{i n}$ and outlet concentration $C_{\text {out }, p}=C_{\text {out }}$. Parcels arriving at the outlet will have experienced a distribution of residence times, so the concentration at the outlet relative to the inlet is

$$
\frac{C_{\text {out }}}{C_{\text {in }}}=\int_{0}^{\infty} g(\tau) f(\tau) d \tau=\int_{0}^{\infty} \operatorname{Gamma}\left(\tau ; k_{R}, \theta_{R}\right) \exp (-k \tau) d \tau=\left(1+\frac{k \bar{\tau}}{N}\right)^{-N}
$$

We modeled temporally dynamic (non-steady) inlet concentrations using a discrete approximation to the above integral, rather than the analytical steady-state solution. Specifically, we considered inlet concentration $C_{\mathrm{in}, t}$ that varies with actual time $t$ such that the outlet concentration at time $t=T$ results from a mixture of water with a range of residence times and a different inlet concentration associated with each residence time. For first-order decay, where the decay of each parcel is independent of variation in concentration due to mixing with other parcels, the output concentration is the integral over all previous times of the product of the corresponding inlet concentrations, residence time probability densities, and decay function values:

$$
C_{\mathrm{out}, T}=\int_{-\infty}^{T} C_{\mathrm{in}, t} g(T-t) f(T-t) d t=\int_{0}^{\infty} C_{\mathrm{in}, T-t} g(t) f(t) d t
$$

which we approximated discretely as:

$$
C_{\mathrm{out}, T} \cong \sum_{i=0}^{i_{\max }} C_{\mathrm{in}, T-i \times \Delta t} g^{*}(i \times \Delta t) f(i \times \Delta t)
$$

where the function $g^{*}$ is the residence time distribution function $g$ normalized to unit sum over a discrete number of values separated by a time step $\Delta t$, and $i_{\max }$ was set large 
enough to include effectively all inlet contributions affecting $C_{\text {out }, T}$. Model parameters are shown in Table 2.

Inlet wetland concentrations were modeled as time series assuming linear interpolation between measured sample concentrations. Because the time period of inlet concentrations that influenced model predictions of outlet concentrations was greater than the four day sampling interval and included the time frame both prior to the initiation and subsequent to the consummation of inlet sampling, two extra parameters were required: pre-sampling $\left(C_{\text {in,pre }}\right)$ and post-sampling inlet $\left(C_{i n, p o s t}\right)$ concentrations (Fig. 2, Table 2). Both parameters were assumed to be constant during a single model run, however in the Bayesian analysis, they were allowed to vary between model runs.

Table 2. Model parameters used for predicting outlet concentrations from known inlet concentrations and model variables.

\begin{tabular}{llcc}
\hline Variable & Type & Symbol & Units \\
\hline \hline Volumetric Decay Constant & Target parameter & $k$ & day $^{-1}$ \\
Pre Inlet Sampling Concentration & Nuisance parameter & $C_{\text {in,pre }}$ & $\mathrm{ppb}$ \\
Post Inlet Sampling Concentration & Nuisance parameter & $C_{\text {in,post }}$ & $\mathrm{ppb}$ \\
Mean Hydraulic Residence Time & Pre-determined parameter & $\bar{\tau}$ & day \\
Number of Tanks in Series & Pre-determined parameter & $N$ & unitless \\
Standard Deviation & Nuisance parameter & $\sigma$ & $\mathrm{ppb}$ \\
Inlet Concentration & Input variable & $C_{\text {in,t }}$ & $\mathrm{ppb}$ \\
Outlet Concentration & Output variable & $C_{\text {out }, t}$ & $\mathrm{ppb}$ \\
Time Step & Constant & $\Delta \tau$ & day \\
Start Time & Constant & $t_{\text {start }}$ & day \\
End Time & Constant & $t_{\text {end }}$ & day \\
\hline
\end{tabular}

\section{BAYESIAN ANALYSIS With MARKOV ChAIN METROPOLIS SAMPLER}

We estimated the parameters of the model using Bayesian analysis (Figure 2). Specifically, we used Metropolis Markov Chain Monte Carlo (MCMC) sampling of the parameter space to estimate the joint posterior distribution of all the model parameters, using a Metropolis-Hastings algorithm for chain construction (Metropolis et al. 1953, Givens et al. 2005, Fan et al. 2006). From this joint distribution, we extracted $95 \%$ credible intervals for each parameter, and drew inference about pesticide decay from the inclusion, or otherwise, of the value zero within the credible interval for the decay parameter, $k$. As with all Bayesian analyses, this required specification of prior 
distributions for each parameter, a model, observed pesticide concentrations, and a likelihood function for measuring the likelihood of any given set of parameter values given the model and the observed data. We assumed normally distributed priors for $N$ and $\bar{\tau}$ with means found during the tracer test (Appendix B), and standard deviations of 0.6 tanks and 0.1 hours respectively. We assumed uniform priors for $C_{\text {in,pre }}$ and $C_{\text {in,post }}$ with ranges between zero and either double the highest observed value in the Salinas region in 2009 and 2010 (acephate), or 1.5 times and 4 times the highest inlet concentration observed during sampling (diazinon and methomyl). We assumed a normal distribution of model errors (differences between model predictions and observed concentrations) with standard deviation $\sigma$, and based the likelihood function on this assumption.

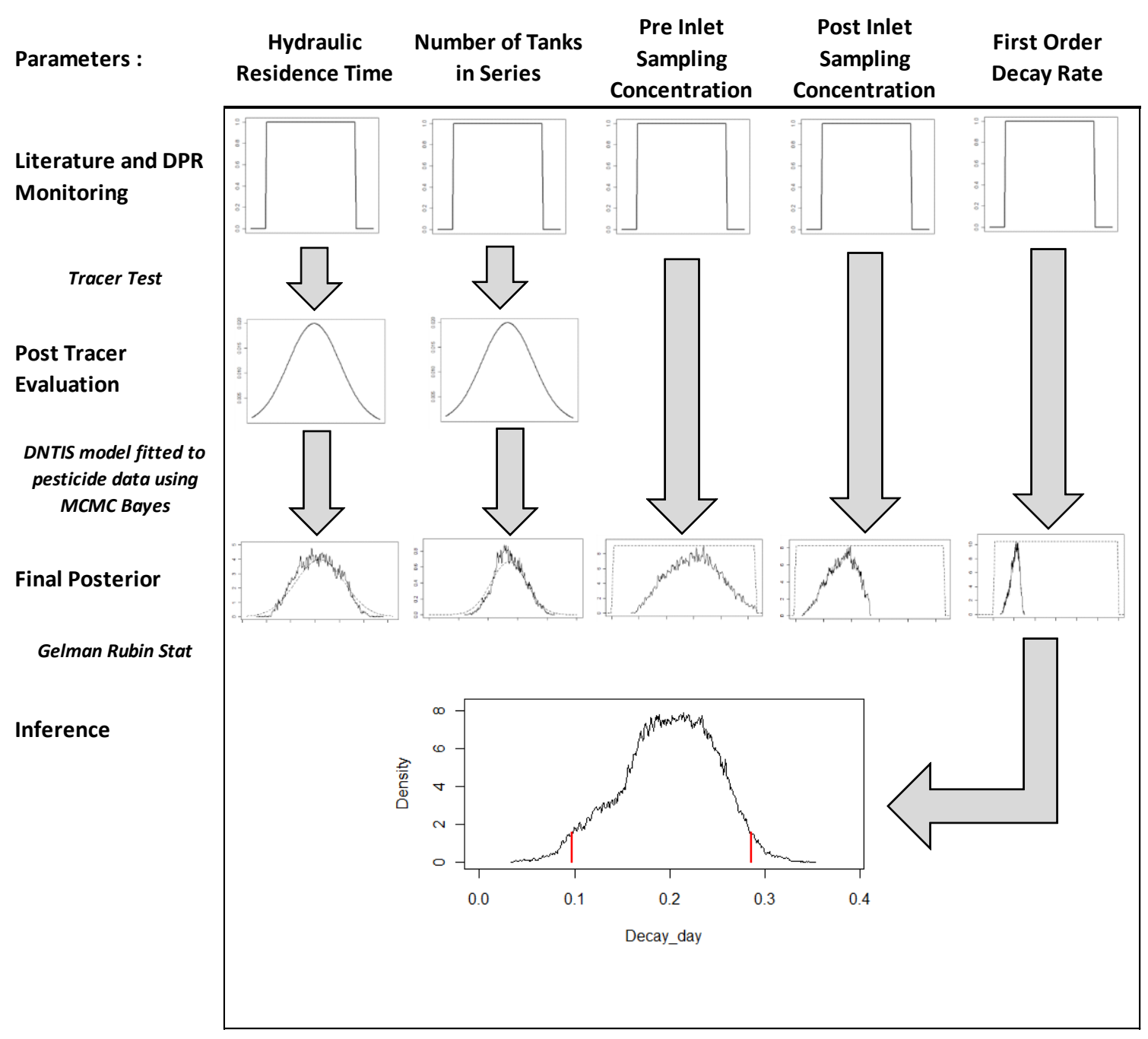

Figure 2. Diagram of Bayesian Framework used for drawing inference regarding the decay rate $95 \%$ credible intervals. The bottom plot shows the summary of all 5 MCMC chains for diazinon and the inferred CI range. 
We used the R Statistical Package (R Development Core Team 2012) to implement the MCMC analysis using five parallel chains of 20,000 runs each with different random starting points. We did this individually for each of the three pesticides. Convergence between similar chains was verified using the BOA package in $\mathrm{R}$ (Smith 2007) and the Brooks-Gelman diagnostic: MPSRF 97.5 percentile < 1.2 with half the chain eliminated as burn-in (Appendix B Table B2) (Givens et al. 2004). The Brooks Gelman statistic estimates how close the chains are to one another and ensures robust and accurate density estimates are constructed from the MCMC chain (Fan et al. 2006). We computed $95 \%$ credible intervals (CI) for all model parameters using the highest posterior density (HPD) (Smith 2005). We inferred decay rates ranged between the 95\% CIs and that pesticide reduction occurred through wetland processes with at least $95 \%$ probability, when the CI interval did not include zero. We also estimated $95 \%$ credible intervals for model predictions by sampling parameter values randomly from the joint posterior distribution, running the model on each draw, and computing $2.5 \%$ and $97.5 \%$ quantiles for the resulting concentrations at each model time step.

\section{RESULTS}

The bromide tracer test supported the theoretical TIS model (Levenspiel 1995, Clark 2009, Kadlec and Wallace 2009) that the RTD for the wetland approximately followed a gamma distribution (Figure 3). We used Bayesian analysis and dynamic TIS model as described previously, setting the decay rate to 0 , to define the most probable values for the wetland hydrology parameters. The most probable value for the number of tanks in series was $\mathrm{N}=16.7$ and for the mean hydraulic residence time was $\bar{t}=5.67$ days. We modified the pumping rate during the pesticide sampling period to achieve $\bar{t}=$ 4.25 days and to have a concentration peak coincident with a 4.0 day sampling interval. 


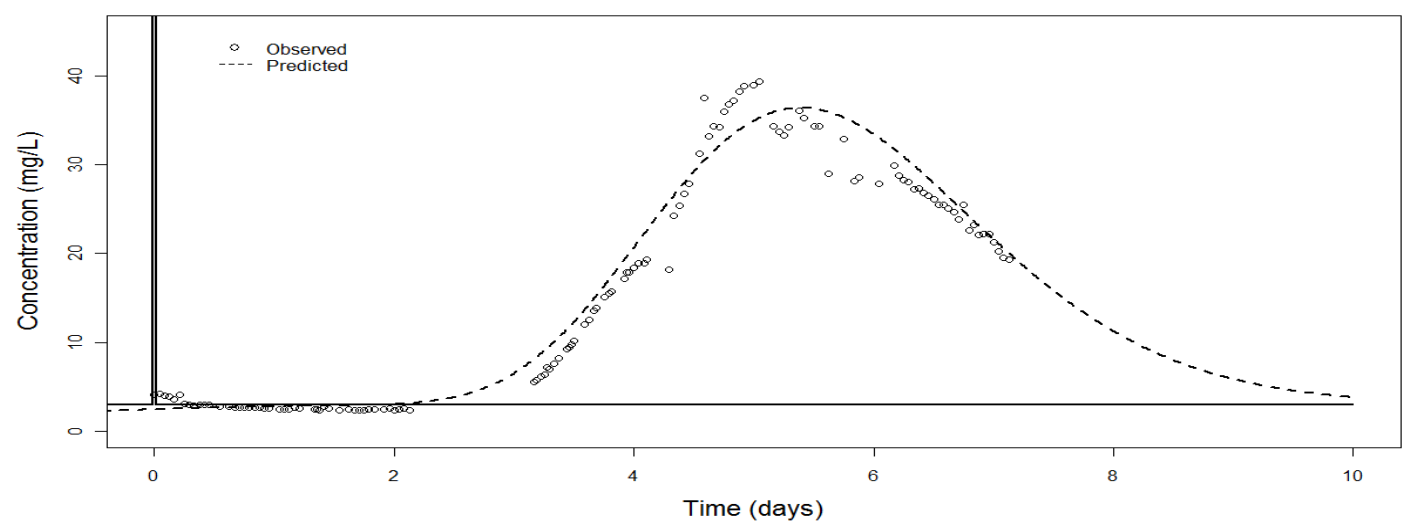

Figure 3. A bromide tracer test was completed prior to pesticide sampling to determine the values of the shape and scale parameters for the gamma distribution representing the Molera wetland hydrology.

The concentrations at the inlet and the outlet for each sampling period are shown in Figure 4 (with numeric data in Table A1). There were no non-detects, nor any trace concentrations during July 2010 sampling. The peak concentrations for diazinon at the inlet exceeded the Criterion Continuous Concentration (CCC) of $0.10 \mathrm{ppb}$ established by the CCRWQCB for aquatic life in the Salinas TMDL (CCRWQCB 2011); however, outlet concentrations were consistently lower. 

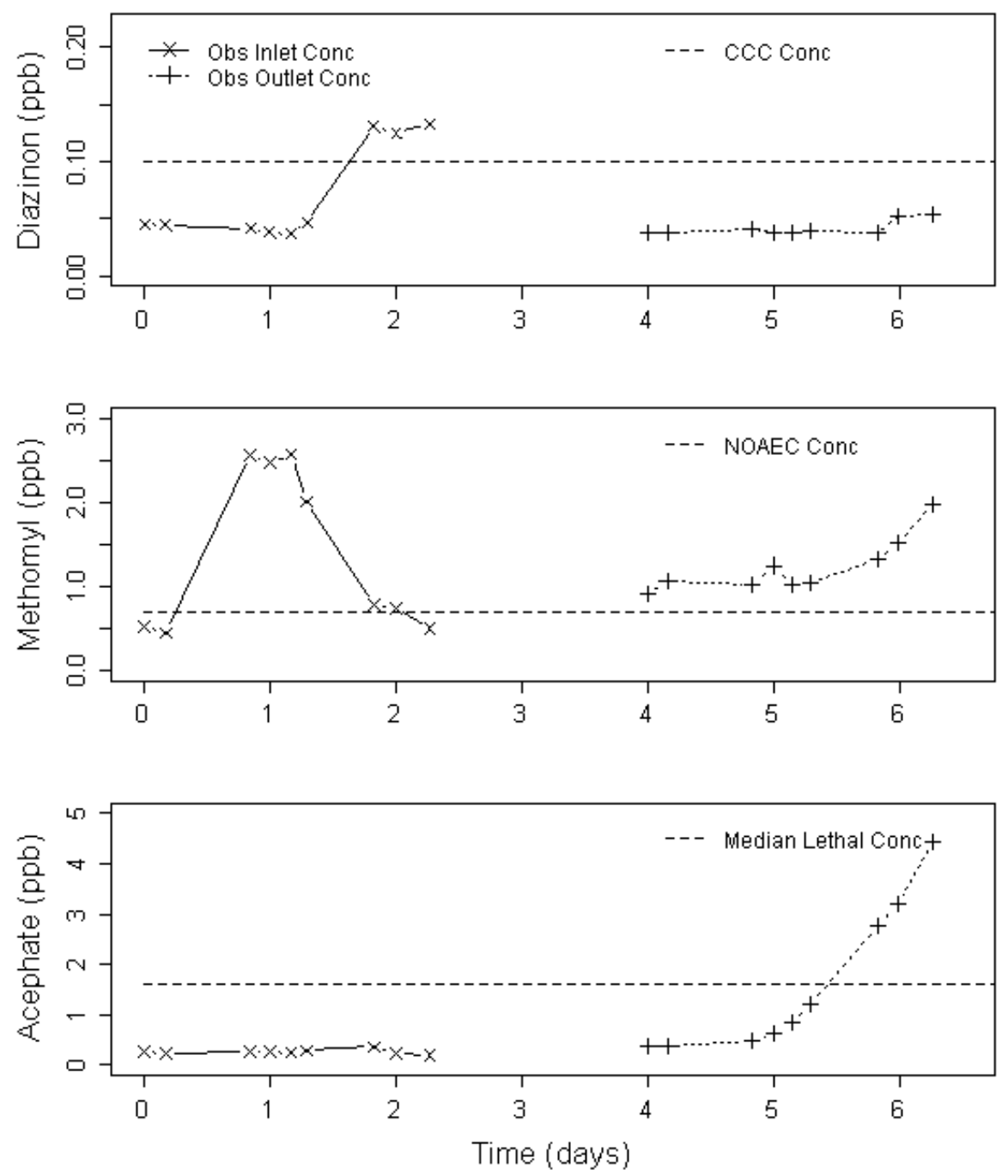

Figure 4. Observed pesticide concentrations at the wetland inlet and outlet during the sampling period from July 5-11, 2010. Different regulatory thresholds are shown for each pesticide, within the range of observed concentrations.

There was substantial evidence that decay occurred for all three pesticides, since the $95 \%$ CIs for their decay parameters did not contain zero (Table 3). Posterior PDF plots for one MCMC chain for each decay rate for each pesticide and week are shown in Figure 5. Brooks-Gelman diagnostics indicated the MCMC chains had converged sufficiently, thus indicating that the resulting Bayesian inference was valid (Table B2). Credible-intervals for predicted outlet concentrations closely bracketed the observed outlet concentrations, despite considerable uncertainty in the pre-sampling and postsampling inlet concentrations (Figure 6). 
Table 3. Credible intervals for pesticide decay rate constants inferred from Bayesian analysis.

\begin{tabular}{lccc}
\hline \multicolumn{1}{c}{ Pesticide } & 95\% Cl low & 95\% Cl high & Most Probable Value \\
\hline \hline Diazinon & 0.097 & 0.289 & 0.184 \\
Methomyl & 0.068 & 0.232 & 0.123 \\
Acephate & 0.068 & 0.246 & 0.175 \\
\hline
\end{tabular}
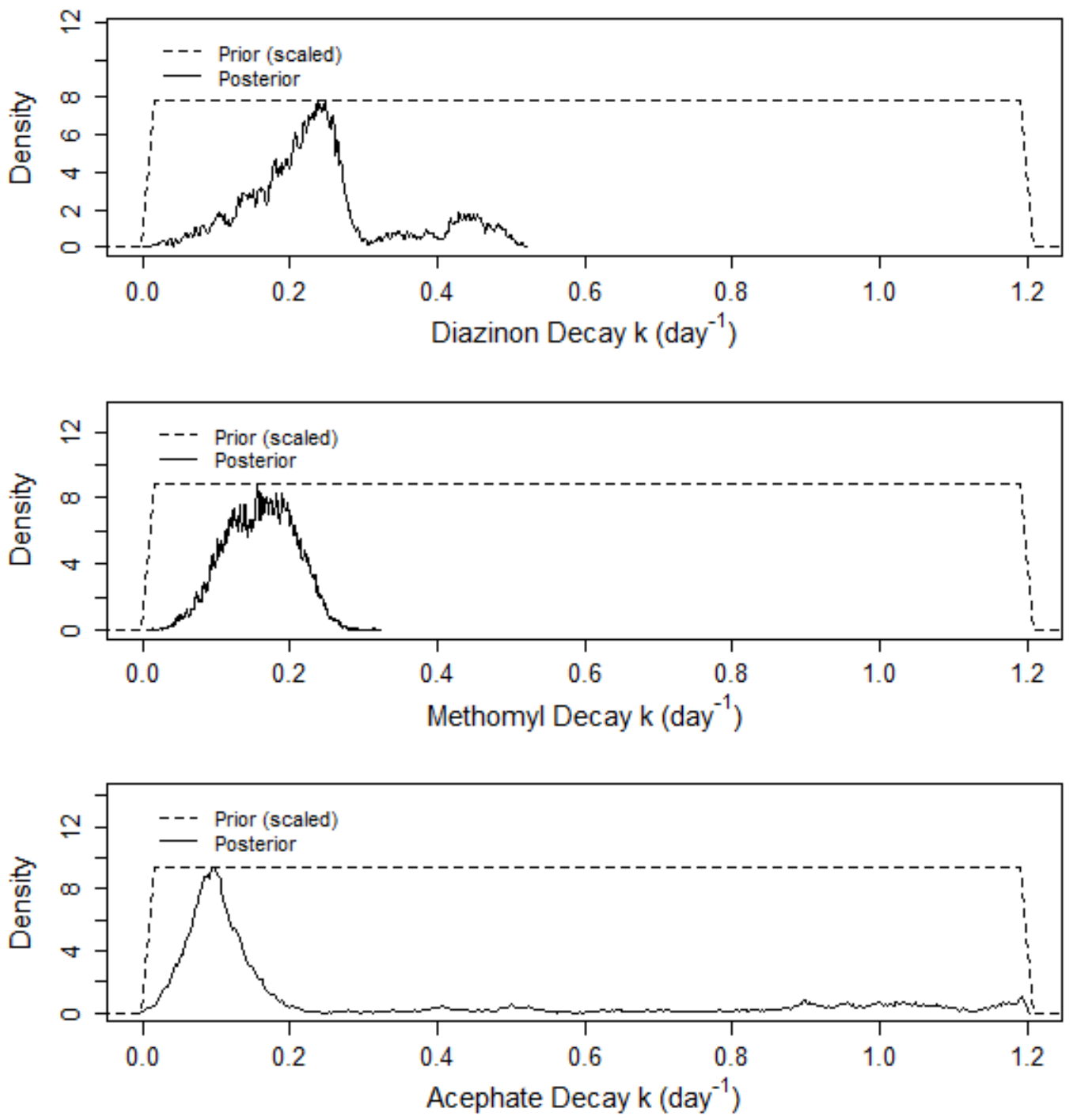

Figure 5: Evidence for decay is shown by the posterior probability distribution functions (pdf) for each pesticide decay rate. Plots display the pdf from the Bayesian MCMC after burnin, from the second half of a 20,000 run chain. 

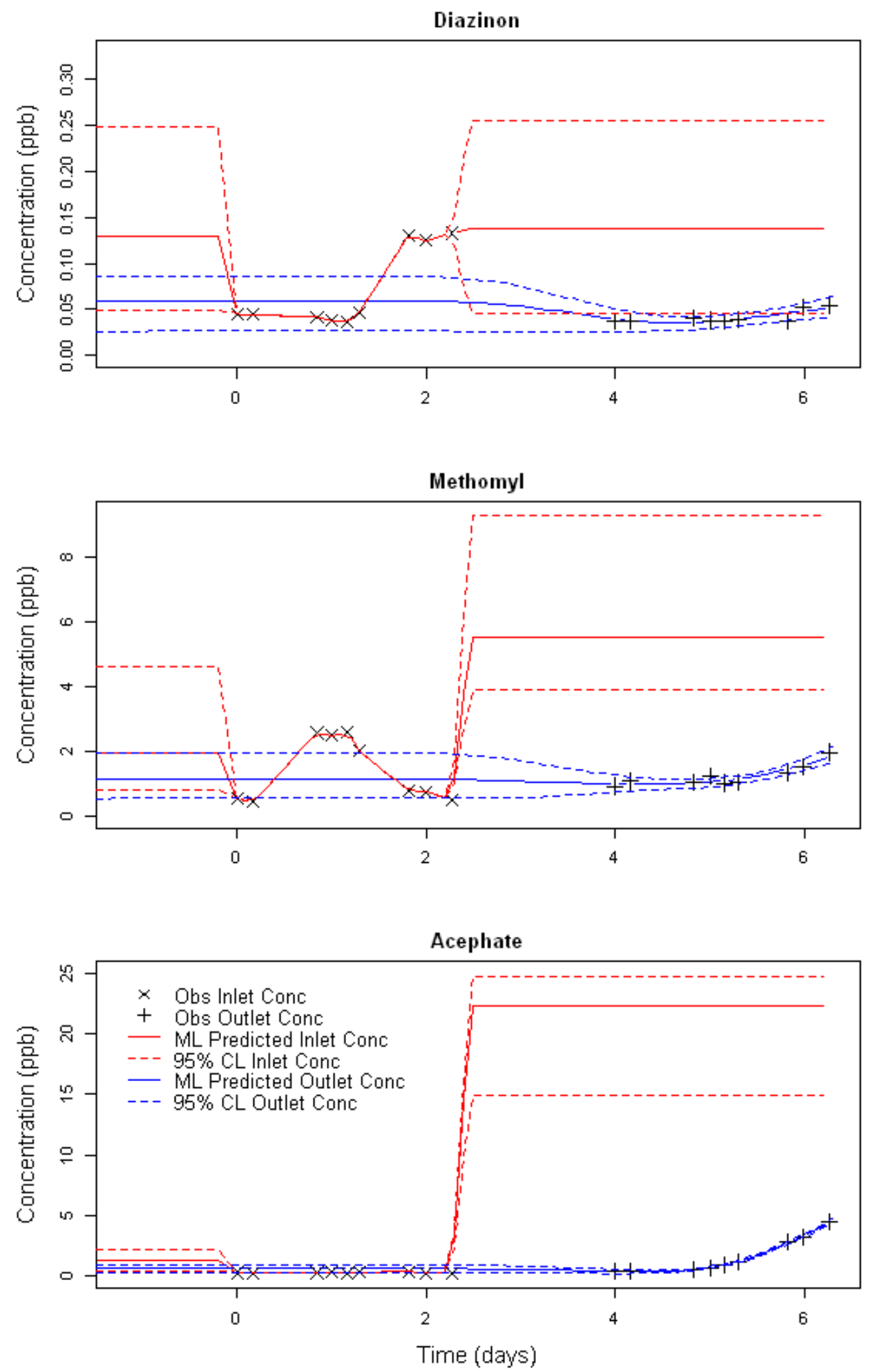

Figure 6. Modeled versus observed inlet and outlet concentrations using most probable values from Bayes for July 5-11, 2010. The 95\% Credible Limits (CL) are shown by dashed lines. 


\section{DISCUSSION}

We found strong support for the postulate that decay occurs for the three water soluble pesticides analyzed. Prior researchers have reported mixed results for diazinon reduction in wetlands, and our literature review did not reveal any results for acephate nor methomyl reduction. Our CI for diazinon decay was 0.097 to 0.289 day $^{-1}$ (which equates to $32 \%$ to $67 \%$ reduction over a four day residence time given the hydrology of the Molera wetland). Matamoros and Salvado (2012) reported positive removal of diazinon from a pond-wetland system in NE Spain with an 8.5 day residence time, computing seasonal removal efficiency between 10-82\%. Budd et al. (2009) computed diazinon reduction between simultaneous samples at the inlet and outlet from a constructed wetland receiving runoff in California's Central Valley and reported a reduction between $-710 \%$ to $82 \%$. They attributed the negative reduction to one high outlet sample, explaining spray drift as a possible reason. Hunt et al. (2008) discussed the reduction of a diazinon peak through a vegetated pond with a 7.4 day RT from over

$10 \mathrm{ppb}$ at the inlet to under $4 \mathrm{ppb}$ at the outlet as the result of hydrological mixing rather than chemical degradation. Moore et al.'s (2008) half life calculations for diazinon in vegetated ditches in Yolo County, CA compute to a decay rate between 2.60 and 3.85 day $^{-1}$.

Our calculation of decay is consistent with established knowledge of wetland processes that act on chemicals. The primary processes for decay or retention of pesticides in wetlands include hydrolysis, photolysis, biodegradation, sorption, and volatilization (Rose et al. 2008). Biodegradation is the most likely pathway of diazinon decay in wetlands and includes metabolism by plants and microbes (Sethunathan et al. 1971, Moore et al. 2007). Other research shows evidence of exponential growth of diazinon degrading microbes in saturated soils (Ghassempour et al. 2002, Fenlon et al. 2011) and of plant metabolism of diazinon (Sethunathan et al. 1971, Montgomery 1997). Hydrolysis of diazinon is more rapid in an acidic environment with $k$ values of 0.0051 day $^{-1}, 0.0037$ day $^{-1}$, and 1.499 day $^{-1}$ respectively at a pH of 9.0, 7.4, and 3.1 (Montgomery 1997). Throughout our study, the $\mathrm{pH}$ varied between 7 and 9, at the lower end of hydrolytic decay. The photolysis decay rate is 0.14 day $^{-1}$ (CADPR 2011); however this rate would be diminished in wetland conditions due to plant shading and turbidity. 
Diazinon is relatively water soluble and has a low sorption coefficient $\left(\mathrm{K}_{\mathrm{OC}}\right)$ of 158 $\mathrm{mL} / \mathrm{g}$ (Montgomery 1997), therefore we assumed there would be minimal change in the amount stored in sediment. Volatilization was likely insignificant, as diazinon has a Henry's Law constant of 0.011 Pascal- $\mathrm{m}^{3} /$ mole (USEPA 2007).

Research of acephate and methomyl degradation in wetland environments is sparse, however, these pesticides degrade by these same processes known to cause chemical breakdown in wetlands. Acephate hydrolyzes at a decay rate of 0.004 and 0.039 day $^{-1}$ in water at a pH of 7.0 and 9.0, respectively, with more rapid hydrolysis at higher pH (Montgomery 1997). Acephate is degraded by bacteria found in soils, metabolized by plants, and degraded by photolysis $\left(\mathrm{k}=0.004\right.$ day $\left.^{-1}\right)$ (Montgomery 1997, Phugare 2012). Methomyl hydrolyzes more rapidly in low $\mathrm{pH}$ with a rate of 0.003 and $0.020 \mathrm{day}^{-1}$ at a pH of 7.0 and 9.0 respectively (Montgomery 1997). Degradation of pesticides by microbes is a rapidly developing field and the species of bacteria and conditions for their growth are being defined in an effort to detoxify pollution in the environment (Mohamed 2009). Wetlands and other biotechnologies can be designed with specific chemical, biological and geophysical characteristics to maximize degradation of specific chemicals of concern in the future, as research confirms the most rapid pathways for decay of the primary chemical and by-products of degradation.

The use of a hydraulic modeling approach was crucial to our result. For example, the naïve interpretation of our acephate data would be that acephate concentrations were being increased by the wetland. However, the most credible interpretation derived using the hydraulic model is that unobserved high concentrations of acephate entered the wetland after we stopped sampling at the inlet, and were dispersed in time such that we observed the arrival of the first traces of this water at the outlet before we stopped sampling. Given that we knew the dispersion rates (from the tracer test), we were able to infer that outlet samples containing these first traces occurred at a lower concentration than if the wetland was not removing acephate - hence the conclusion that acephate removal most likely occurred.

Our deduction that decay occurred for these three pesticides is supported by the results of our analysis and the degradation processes known to occur in wetlands, however it is important to note the limitations of our model. The credible intervals we 
derived for the decay rates of the three pesticides were based on several assumptions: a closed system with regard to air, no change in the amount of chemical stored in sediments, constant pre-sampling and post-sampling inlet concentrations, and the definition of the priors. It is possible that pesticides entered the wetland through spray drift or atmospheric deposition with the morning fog. Spray drift has been attributed to spikes at wetland outlets for other pesticide studies (Gregoire et al. 2009, Budd et al. 2010). Atmospheric deposition was feasible as all three pesticides are moderately volatile yet have a low Henry's law coefficient (Montgomery 1997, UH 2012); however review of the pesticide use records for the sampling period reveal only methomyl was applied aerially within a 5 mile radius of the wetland (DPR 2012). On the final day of outlet sampling, methomyl was applied by helicopter within the Section (27M13S02E30) containing the wetland ten minutes prior to the first morning sample, thus possibly contributing atmospheric deposition to the increased concentration seen at the outlet on the final day of sampling. Our assumption that a constant amount of pesticide resided in soil and on plant surfaces, lead us to exclude this dynamic from the model. However in a study of two parallel vegetated ditches, Moore et al. (2007) found that the relative amounts of diazinon partitioned to soil, plant and water (averaging 54\%, 38\% and 8\% respectively) was dynamic temporally as well as spatially. Somewhat confounding their result was the drying of the ditch due to infiltration, possibly driving diazinon into bed sediments. Conversely, Hunt et al. (2008) did not detect diazinon in bed sediments even when present in the inlet water at a concentration above $9 \mathrm{ppb}$. Additionally, we assumed that pre-sampling and post-sampling inlet concentrations were constant for a model run whereas in reality these concentrations are dynamic and highly variable, however this assumption probably had little influence on the outcome of the Bayesian analysis. Finally, the definition of the range of the priors allowed for a relatively high postsampling inlet concentration and the distribution was set as uniform for the inlet concentration variables. The CIs for the post sampling inlet variable for methomyl (95\% CI between 3.77 and $9.37 \mathrm{ppb}$ ) and acephate (95\% CI between 15.35 to $25.0 \mathrm{ppb} 95 \%$ ) concentrations are plausible, however defining their form as a gamma or beta distribution rather than uniform may have been more accurate. Furthermore, a longer sampling 
interval, especially at the inlet, would increase confidence in model results; however the high expense of pesticide monitoring and analysis limited our sample size.

Constructed wetlands have the potential to remove or reduce concentrations of several agricultural chemicals simultaneously; however computing optimal wetland size is important in order to achieve degradation of relevant agro-chemicals while minimizing the acreage removed from production. Credible intervals for decay constants are of considerable design value because they can be used for determining a size range appropriate for wetland treatment. Through hydrologic modeling and Bayesian analysis we computed the CIs for three water soluble pesticides. Assuming steady state concentrations, the wetland land area requirements based on the credible intervals for diazinon decay $\left(0.097\right.$ day $^{-1}$ to 0.289 day $\left.^{-1}\right)$ for a farm operation discharging at a rate of $100 \mathrm{~m}^{3} /$ day with a steady state inlet diazinon concentration of $0.8 \mathrm{ppb}$ would range between $2860 \mathrm{~m}^{2}$ and $8522 \mathrm{~m}^{2}$ to achieve the $0.1 \mathrm{ppb}$ CCC threshold required by the Lower Salinas watershed TMDL. Our assumptions included a depth of $0.33 \mathrm{~m}$ and an N of 4 for the treatment wetland.

\section{CONCLUSION}

Strong quantitative evidence was found for the decay of diazinon and acephate within the Molera wetland. Wetland degradation of all three pesticides was substantiated by our statistical results, as we found the $95 \%$ CI for the decay rates for all three pesticides spanned a positive range that did not include zero. However, aerial spraying of methomyl within a 1 mile radius during outlet sampling may have resulted in atmospheric deposition, thus confounding the decay rate determined for this pesticide. Because our method and analysis accounted for important hydraulic processes often not addressed by researchers in calculating chemical degradation in wetlands, our results are more robust to uncertainty. Specifically, we modeled wetland hydrology and followed an inlet and outlet sampling interval matching the hydraulic retention time, and we accounted for the uncertainty of our decay parameter through a Bayesian analytical approach. Because our methodology accounted for these factors, the derived decay rates are relatively reliable and have validity for preliminary use in determining wetland sizing for the mitigation of these pesticides. Additional studies with a longer inlet sampling 
interval could validate and refine our credible intervals for the decay rates so that wetland designers and agricultural managers could increase their confidence in the applicability of these rates to wetland design. Further research of the specific wetland physical and biochemical properties for removal of target agro-chemicals could help reduce the wetland footprint and increase receptivity to investing in wetlands for removing multiple agrochemical contaminants.

\section{BIBLIOGRAPHY}

Abu-Reesh IM, Abu-Sharkh BF. 2003. Comparison of axial dispersion and tanks-inseries models for simulating the performance of enzyme reactors. Industrial \& Engineering Chemistry Research. 42: 5495-5505.

Anderson BS, Hunt JW, Phillips BM, Nicely PA, Gilbert KD, Vlaming VD, Connor V, Richard N, Tjeerdema RS. 2003a. Ecotoxicological impacts of agricultural drain water in the Salinas River, CA USA. Environmental Toxicology and Chemistry 22: $2375-2384$.

Anderson BS, Hunt JW, Phillips BM, Nicely PA, Gilbert KD, Vlaming VD, Connor V, Richard N, Tjeerdema RS. 2003b. Integrated assessment of the impacts of agricultural drainwater in the Salinas River (California, USA). Environmental Pollution 124: 523 - 532.

Anderson B, Phillips B, Hunt J, Siegler K, Vorhees J, Smalling K, Kuvila K, Adams M. 2010. Watershed-scale evaluation agricultural BMP effectiveness in protecting critical coastal habitats: Final report on the status of three Central California estuaries to the Central Coast Regional Water Quality Control Board, San Luis Obispo, CA, USA, pp.

Anderson BS, Phillips BM, Hunt JW, Largay B, Shihadeh R, Tjeerdema RS. 2011. Pesticide and toxicity reduction using an integrated vegetated treatment system. Environmental Toxicology and Chemistry. 30(5):1036-1043.

Bennett ER, Moore MT, Cooper CM, Smith S, Shields FD, Drouillard KG, Schulz R. 2005. Vegetated agricultural drainage ditches for the mitigation of pyrethroid-associated runoff. Environmental Toxicology and Chemistry. 24(9):2121-2127. 
Bondarenko S. Gan J. 2004. Degradation and sorption of selected organophosphate and carbamate insecticides in urban stream sediments. Environmental Toxicology and Chemistry. 23(8):1809-1814.

Bouchard MF, Chevrier J, Harley KG, Kogut K, Vedar M, Calderon N, Trujillo C, Johnson C, Bradman A, Barr DB, Exkenazi B. Prenatal exposure to organophosphate pesticides and IQ in 7-year-old children. Environmental Health Perspectives. 19:1189-1195.

Budd R, O'Geen A, Goh KS, Bondarenko S, Gan J. 2009. Efficacy of constructed wetlands in pesticide removal from tailwaters in the Central Valley, California. Environmental Science and Technology. 43:2925-2930.

California Department of Pesticide Regulation. 2006. Determination of carbamate pesticides in water samples: Method \#305, Dated: 3/1/06. [Internet]. [cited 2010 April 31]. Available from: http://www.cdpr.ca.gov/docs/emon/pubs/anl_methds/imeth_305.pdf

California Department of Pesticide Regulation. 2007. Determination of organophosphorous pesticides in water samples: Method \#307, Revision \#9, Updated 2/22/07. [Internet]. [cited 2010 April 31]. Available from: http://www.cdpr.ca.gov/docs/emon/pubs/anl_methds/imeth_307.pdf

California Department of Pesticide Regulation. 2008. Determination of acephate and methamidophos in surface water by LC-MS. Method \#313, Original Date 7/18/08. [Internet]. [cited 2011 April 31]. Available from: http://www.cdpr.ca.gov/docs/emon/pubs/anl methds/imeth 313.pdf.

California Department of Pesticide Regulation [CADPR]. 2011. A record of achievement 2010-2011 progress report. [Internet]. [cited 2012 April 10]. http://www.cdpr.ca.gov/docs/dept/progrpt/current/pdf files/report.pdf

California Department of Pesticide Regulation. 2012. Pesticide Information Portal, Pesticide Use Report (PUR) data. . [Internet]. [cited 2012 April 10]. Available at http://calpip.cdpr.ca.gov/main.cfm

California State Water Resources Control Board [SWRCB]. 2008. Approving an amendment to the water quality control plan for the Sacramento and San Joaquin River Basins 
(Basin Plan) for the control of diazinon and chlorpyrifos runoff into the Sacramento and Feather Rivers. Resolution No. 2008-0013.

Central Coast Regional Water Quality Control Board [CCRWQCB]. 2011. Total maximum daily loads for chlorpyrifos and diazinon in lower Salinas River watershed in Monterey County, California. Final project report. April 2011.

Central Coast Water Quality Preservation, Inc. [CCWQPI] . 2008. Phase I follow-up water quality monitoring: organophosphate pesticide sampling final data report. Central Coast region conditional waiver cooperative monitoring program. May 19, 2008. [Internet]. [cited 2012 April 10]. http://www.ccamp.org/ccamp/Reports.html\#AgReports.

Central Coast Water Quality Preservation [CCWQP]. 2009. Supplemental Water Quality Monitoring for Organophosphate Pesticides and Aquatic Toxicity, Central Coast Region Conditional Ag Order [Internet]. [cited 2012 April 10]. http://www.ccamp.org/ccamp/Reports.html\#AgReports.

Central Coast Water Quality Preservation [CCWQP]. 2010. Pesticides and toxicity to Hyalella azteca in sediments. Watsonville, CA, USA. December 2010.

Clark, MM. 2009. Transport Modeling for environmental engineers and scientists $-2^{\text {nd }}$ ed. Hoboken, NJ: A John Wiley \& Sons, Inc.

Chazarenc F, Merlin G, Gonthier Y. 2003. Hydrodynamics of horizontal subsurfeace flow constructed wetlands. Ecological Engineering. 21: 165-173.

Fan Y, Brooks YF, Gelman A. 2006. Output assessment for Monte Carlo simulations via the score statistic. Journal of Computational and Graphical Statistics. 15(1):178206.

Fenlon KA, Jones KC, Semple KT. 2011. The effect of soil:water ratios on the induction of isoproturon, cypermethirin, and diazinon mineralisation. Chemosphere 82:163168.

Ghassempour A, Mohammadkhah A, Najafi F, Rajabzadeh M. 2002. Monitoring of the pesticide diazinon in soil, stem and surface water of rice fields. Analytical Sciences 18:779-783.

Gelman A, Carlin JB, Stern HS, Rubin DB. 2004. Bayesian data analysis (second edition). New York: CRC Press. 
Givens GH, Hoeting JA. 2005. Computational statistics. Hoboken, New Jersey: John Wiley \& Sones, Inc.

Gregoire C, Elsaesser D, Huguenot D, Lange J, Lebeau T, Merli A, Mose R, POasseport E, Payraudeau S, Schutz T, Schulz R, Padilla G, Tournebize J, Trevisan M, Wanko A. 2009. Mitigation of agricultural nonpoin-source pesticide pollution in artificial wetland systems. Envionmental Chemistry Letters, 7:205-231.

Harris, K., Watson, F., Brown, K., Burton, R., Carmichael, S., Casagrande, J.M., Casagrande, J.R., Daniels, M., Earnshaw, S., Frank, D., Hanson, E., Lienk, L.L., Martin, P., Travers, B., Watson, J., \& Wiskind, A. (2007) Agricultural Management Practices and Treatment Wetlands for Water Quality Improvement in Southern Monterey Bay Watersheds: Final Report. Report to California State Water Resources Control Board. The Watershed Institute, California State Monterey Bay, Publication No. WI-2007-01, 162.

Hunt J, Anderson B, Phillips B, Tjeerdema R, Richard N, Connor V, Worcester K, Angelo M, Bern A, Fulfrost B, Mulvaney D. 2006. Spatial relationships between water quality and pesticide application in agricultural watersheds. Environmental Monitoring and Assessment 121:245-262.

Hunt J, Anderson B, Phillips B, Tjeerdema R, Largay B, Beretti M, Bern A. 2008. Use of toxicity identification evaluations to determine the pesticide mitigation effectiveness of on-farm vegetated treatment systesm. Environmental Pollution 156:348-358.

Kadlec RH, Knight R. 1996. Treatment wetlands (first edition). New York: CRC Press. Kadlec RH. 2005. Nitrogen farming for pollution control. Journal of Environmental Science and Health 40: 1307-1330.

Kadlec RH, Wallace SD. 2009. Treatment wetlands (second edition). New York: CRC Press.

Kiene RP, Capone DG. 1986. Stimulation of methanogenisis by aldicarb and serveral other N-Methyl carbamate pesticides. Hudson River Foundation Grant 14-83B12, EPA Grant R-809475-01-0, NOAA Grant NA-80-RAD-0057. 
Kroger MT, Moore MT, Cooper CM, Holland MM. 2009. Diazinon accumulation and dissipation in Oryza sativa L. following simulated agricultural runoff amendment in flooded rice patties. Water, Air \& Soil Pollution. 201:209-218.

Labenia JS, Baldwin DH, French BL, Jay W. Scholtz SL. 2007. Behavioral impairment and increased predation mortality in cutthroat trout exposed to carbaryl. Marine Ecology Progress Series. 329:1-11.

Larkin DJ, Tjeerdema RS. 2000. Fate and effects of Diazinon. Review of Environmental Contamination and Toxicology. 166: 49-82.

Levenspiel O. 1998. Chemical reaction engineering. New York: John Wiley \& Sons.

Massoudieh A, Bombardelli FA, Ginn TR. 2010. A biogeochemical model of contaminant fate and transport in river waters and sediment. Journal of Contaminant Hydrology. 112:103-117.

Metropolis N, Rosenbluth AW, Rosenbluth MN, Teller AH, Teller E. 1953. Equation of state calculations by fast computing machines. Journal of Chemical Physics 21(6): 1087-1092.

Matamoros V, Salvado V. 2012. Evaluation of the seasonal performanca or a water reclamation pond-constructed wetland system for removing emerging contaminants. Chemosphere 86:111-117.

Mohamed MS. 2009. Degradation of methomyl by the novel bacterial strain Stetnotrophomonas maltophilia M1. Electronic Journal of Biotechnology. 12(4), 1:6.

Monterey County Agricultural Commissioner's Office [MCAC] . 2011. Monterey County Crop Report 2010. Internet cited 4/8/12. Available at http://ag.co.monterey.ca.us/assets/resources/assets/163/cropreport_2010.pdf.

Monterey Peninsula Chamber of Commerce [MPCC]. 2012. Key Industries. http://www.mpcc.com/about-peninsula/key-industries.php

Montgomery JH. 1997. Agrichemicals desk reference. Boca Raton, Florida: CRC Press LLC.

Moore MT, Cooper CM, Smith S, Cullum RF, Knight SS, Locke MA, Bennett ER. 2007. Diazinon mitigation in constructed wetlands: influence of vegetation. Water, Air, Soil Pollution 184:313-321. 
Moore MT, Denton DL, Cooper CM, Wrysinski J, Miller JL, Reece K, Crane D, Robins R. 2008. Mitigation assessment of vegetated drainage ditches for collecting irrigation runoff in California. Journal of Environmental Quality 37: 486-493.

Moore MR, Lizotte RE, Kroger R. 2009. Efficiency of experimental rice (Oryza sativa L.) fields in mitigating diazinon runoff toxicity to Hyalella azteca. Bulletin of Environmental Contaimniation and Toxicology 82: 777-780.

National Pesticide Information Center [NPIC]. 209. Diazinon technical fact sheet. Oregon State University. http://npic.orst.edu/factsheets/diazinontech.pdf Nauman EB, Buffham BA. 1983. Mixing in continuous flow systems. New York: John Wiley \& Sons.

Patterson M. 2004. Appendix to Acephate analysis of risk to endangered and threatened salmon and steelhead. EPA Report dated Feb 9, 2004. Environmental Field Branch Office of Pesticide Programs.

Persson J, Somes NL, Wong TH. 1999. Hydraulics efficiency of constructed wetlands and ponds. Water Science and Technology. 3:291-300.

Pfaff JD. 1993. Method 300.0 Determination of inorganic anions by ion chromatography. Revision 2.1 August 1993. USEPA, Office of Research and Development, Cincinnati, $\mathrm{OH}$.

Phygare SS, Gaikwad YB, Jadhav JP. 2012. Biodegradation of acephate using a developed bacterial consortium and toxicological analysis using earthworms (Lumbricus terrestris) as a model animal. International Giodeterioration \& Biodegradation. 69:1-9.

R Development Core Team. 2011. R: A language and environment for statistical computing. R Foundation for Statistical Computing, Vienna, Austria. ISBN 3900051-07-0, http://www.R-project.org/.

Reichenberger S, Bach M, Skitschak A, Frede H. 2007. Mitigation strategies to reduce pesticide inputes into ground and surface water and their effectiveness; a review. Science of the Total Environment, 384:1-35.

Rose MT, Crossan AN, Kennedy IR. 2008. The effect of vegetation on pesticide dissipation from ponded treatment wetlands: quantification using a simple model. Chemosphere. 72:999-1005. 
Runkel RL, Broshears RJ. 1991. One-dimensional transport wiht inflow and storage (OTIS): a solute transport model for small streams. CADWEST Technical Report 91-01, September 30, 1991.

Sethunathan N, Caballa S, Pathar MD. 1971. Absorption and translocation of diazinon by rice plants from submerged soils and paddy water and the persistance of residues in plant tissues. 1971. Journal of Economic Entomology 64:571-576.

Schulz R. 2004. Field studies on exposure, effects, and risk mitigation on aquatic nonpoint source insecticide pollution: A review. Journal of Environmental Quality. 37:486-493.

Smith B. 2005. Bayesian output analysis program (BOA) user's manual, Version 1.1.5 for R. Dept. of Biostatistics, College of Public Health, University of Iowas. [Internet]. [cited 2011 March 31]. Available from: http://www.publichealth.uiowa.edu/boa.

Smith BJ. 2007. boa: An R Package for MCMC Output Convergence Assessment and Posterior Inference Journal of Statistical Software, 21(11), 1-37

Starner K. 2010. Monitoring results Molera Wetland input 2009 DPR study 259 \& 252. (personal communication)

Starner K. 2012. Memorandum: Availability of the Department of Pesticide Regulations Surface Water Monitoring Results, 2008-2010. January 11, 2012 memorandum to John S Sanders. http://www.cdpr.ca.gov/docs/emon/pubs/ehapreps/study_252_262_starner.pdf

Stehle S, Elsaesser D, Gregoire C, Imfeld G, Niehaus E, Passeport E, Payraudeau S, Schafer RB, Tournebize J, Schulz R. 2011. Pesticide mitigation by vegetated treatment systems: a meta-analysis. Journal of Environmental Quality 40:10681080.

Tierney KB. Singh C, Ross PS, Kennedy CJ. 2007. Relating olfactory neruotoxicity to altered olfactory-mediated behavios in rainbow trout exposed to three currentlyused pesticides. Aquatic Toxicity. 81(1):55-64.

Trumble JT, Butler CD. 2009. Climate change will exacerbate California's insect pest problems. California Agriculture, 63:73-78. 
Werner Tm, Kadlec RH. 2000. Wetland residence time distribution modeling. Ecological Engineering 15: 77-90.

Tierney KB. 2007. Neurotoxicity of pesticides to salmon: Physiology to ethology. Retrieved from http://search.proquest.com/docview/20447203?accountid=10355.

Tillman D, Fargione J, Wolff B, D'Antonio C, Dobson A, Howarth R, Schindler D, Schlesinger WH, Simberloff D, Swackhamer D. 2001. Forecasting agriculturally driven global environmental change. Science. April 13, 2001, 292: 281-284.

University of Herfordshire [UH]. 2012. Pesticide Properties Database. Internet: http://sitem.herts.ac.uk/aeru/footprint/en/

U.S. Environmental Protection Agency [USEPA]. 2007. Risk of Diazinon Use to the Federally Listed Endangered Barton Springs Salamander (Eurycea sosorum). Office of Preventions, Pesticides and Toxic Substances, Office of Pesticide Programs, U.S. Government Printing Office: Washington, DC.

US Environmental Protection Agency [EPA]. 2010. Problem formulation for the environmental fate, ecological risk, endangered species, and drinking water exposure assessments in support of the registration review of methomyl. 7/16/2010. Washington DC. CAS Reg: 16752-77-5

Xu S, Worman A, Dverstorp B. 2007. Criteria for resolution-scales and parameterisation of compartmental models of hydrological and ecological mass flows. Journal of Hydrology. 335 (issues 3-4): 364-373.

Zhang X, Starner K. 2011. Analysis of diazinon agricultural use in regions of frequent surface water detections. California Department of Pesticide Regulation. Sept. 13, 2011. 


\section{APPENDIX A SAMPLING RESULTS}

This appendix depicts results for pesticide concentrations and other water quality parameters (nitrate and chloride) for both weeks of sampling (July and August 2010). The chloride concentrations entering the wetland inlet during August sampling were highly variable (Figure A1). This variability indicated mixing of tidal water in the Tembladero Slough where wetland inlet water was drawn. We were unable to predict the percent mix of fresh water to tidal water entering the wetland as several factors could have influenced the timing and amount of salt water entry including wind speed and direction, tide height and the rate of movement of tidal water up the Slough. Due to this uncertainty, we were not able to model the fresh water portion of inlet concentrations entering the wetland during Week 2 of sampling; and therefore we were unable to include Week 2 in our analysis.

During the first week of sampling, tidal influence and saline mixing of inlet water was not observed during inlet sampling. The period of inlet water sampling for analysis of ions including chloride and nitrate was longer in duration (4 days) than the sampling period for pesticides (2.3 days). Although a chloride peak was observed at about 3.5 days, this salt water entry occurred after inlet sampling had ended. 
Table A1. Matching pesticide concentrations at the wetland inlet and outlet during the two sampling periods. Sampling period 2 was eliminated from our analysis due to salt water mixing at the inlet during week 2 of pesticide sampling. The degradate of acephate, methamidophos, was also analyzed with all non-detect results at both the inlet and outlet.

\begin{tabular}{ccccc|ccccc}
\multicolumn{5}{c}{ INLET } & \multicolumn{5}{c}{ OUTLET } \\
Date & Time & $\begin{array}{c}\text { Diazinon } \\
\text { (ppb) }\end{array}$ & $\begin{array}{c}\text { Methomyl } \\
\text { (ppb) }\end{array}$ & $\begin{array}{c}\text { Acephate } \\
\text { (ppb) }\end{array}$ & Date & Time & $\begin{array}{c}\text { Diazinon } \\
\text { (ppb) }\end{array}$ & $\begin{array}{c}\text { Methomyl } \\
\text { (ppb) }\end{array}$ & $\begin{array}{c}\text { Acephate } \\
\text { (ppb) }\end{array}$ \\
\hline \hline $7 / 5 / 2010$ & 1300 & 0.0455 & 0.527 & 0.258 & $7 / 9 / 2010$ & 1300 & 0.0381 & 0.917 & 0.367 \\
$7 / 5 / 2010$ & 1700 & 0.0445 & 0.447 & 0.236 & $7 / 9 / 2010$ & 1645 & 0.0373 & 1.062 & 0.371 \\
$7 / 6 / 2010$ & 915 & 0.0417 & 2.566 & 0.266 & $7 / 10 / 2010$ & 900 & 0.0407 & 1.031 & 0.497 \\
$7 / 6 / 2010$ & 1255 & 0.0381 & 2.483 & 0.273 & $7 / 10 / 2010$ & 1310 & 0.0382 & 1.25 & 0.62 \\
$7 / 6 / 2010$ & 1700 & 0.0366 & 2.574 & 0.244 & $7 / 10 / 2010$ & 1645 & 0.0375 & 1.013 & 0.861 \\
$7 / 6 / 2010$ & 2000 & 0.047 & 2.01 & 0.286 & $7 / 10 / 2010$ & 2010 & 0.0396 & 1.049 & 1.21 \\
$7 / 7 / 2010$ & 845 & 0.1307 & 0.776 & 0.363 & $7 / 11 / 2010$ & 855 & 0.0379 & 1.331 & 2.76 \\
$7 / 7 / 2010$ & 1300 & 0.1248 & 0.739 & 0.238 & $7 / 11 / 2010$ & 1255 & 0.052 & 1.529 & 3.19 \\
$7 / 7 / 2010$ & 1930 & 0.1326 & 0.497 & 0.202 & $7 / 11 / 2010$ & 1925 & 0.0539 & 1.969 & 4.44 \\
& & & & & & & & & \\
$8 / 2 / 2010$ & 1258 & 0.0943 & 0.16 & 0.311 & $8 / 6 / 2010$ & 1300 & 0.0438 & 0.183 & 0.296 \\
$8 / 2 / 2010$ & 1700 & ND & $\operatorname{Tr}(0.041)$ & ND & $8 / 6 / 2010$ & 1700 & 0.0576 & 0.195 & 0.281 \\
$8 / 3 / 2010$ & 855 & 0.1195 & 0.332 & ND & $8 / 7 / 2010$ & 900 & 0.0566 & 0.13 & $\operatorname{Tr}(0.225)$ \\
$8 / 3 / 2010$ & 1255 & ND & 0.05 & ND & $8 / 7 / 2010$ & 1300 & 0.0602 & 0.146 & $\operatorname{Tr}(0.200)$ \\
$8 / 3 / 2010$ & 1650 & ND & 0.051 & ND & $8 / 7 / 2010$ & 1700 & 0.0508 & 0.132 & $\operatorname{Tr}(0.189)$ \\
$8 / 3 / 2010$ & 1930 & ND & 0.051 & ND & $8 / 7 / 2010$ & 1930 & 0.0515 & 0.127 & $\operatorname{Tr}(0.218)$ \\
$8 / 4 / 2010$ & 900 & 0.1078 & 0.133 & 0.253 & $8 / 8 / 2010$ & 900 & 0.0509 & 0.117 & $\operatorname{Tr}(0.178)$ \\
$8 / 4 / 2010$ & 1300 & 0.0103 & $\operatorname{Tr}(0.046)$ & ND & $8 / 8 / 2010$ & 1255 & 0.0516 & 0.115 & $\operatorname{Tr}(0.221)$ \\
$8 / 4 / 2010$ & 1655 & ND & $\operatorname{Tr}(0.041)$ & ND & $8 / 8 / 2010$ & 1700 & 0.0478 & 0.125 & $\operatorname{Tr}(0.226)$ \\
\hline
\end{tabular}

- $\operatorname{Tr}$ refers to Trace amount detected. ND is a non-detect.

\begin{tabular}{lll}
\hline \multicolumn{2}{l}{ Reporting Limits } & \\
\hline \hline Diazinon & 0.01 & $\mathrm{ppb}$ \\
Methomyl & 0.05 & $\mathrm{ppb}$ \\
Acephate & 0.25 & $\mathrm{ppb}$ \\
\hline
\end{tabular}


Figure A1: Plots of chloride and nitrate concentrations during July and August sampling periods demonstrate the influence of tidal waters on inlet concentrations. Swings in chloride concentrations in August were due to tidal mixing of ocean water in the Tembladero Slough where inlet water is pumped into the wetland. Nitrate concentrations were inversely proportional to chloride concentrations, in part explained by the lower fraction of contribution by fresh water runoff in these samples. Although there was a chloride spike at the inlet during July sampling, the timing of this saline entry was after inlet pesticide sampling had ended.
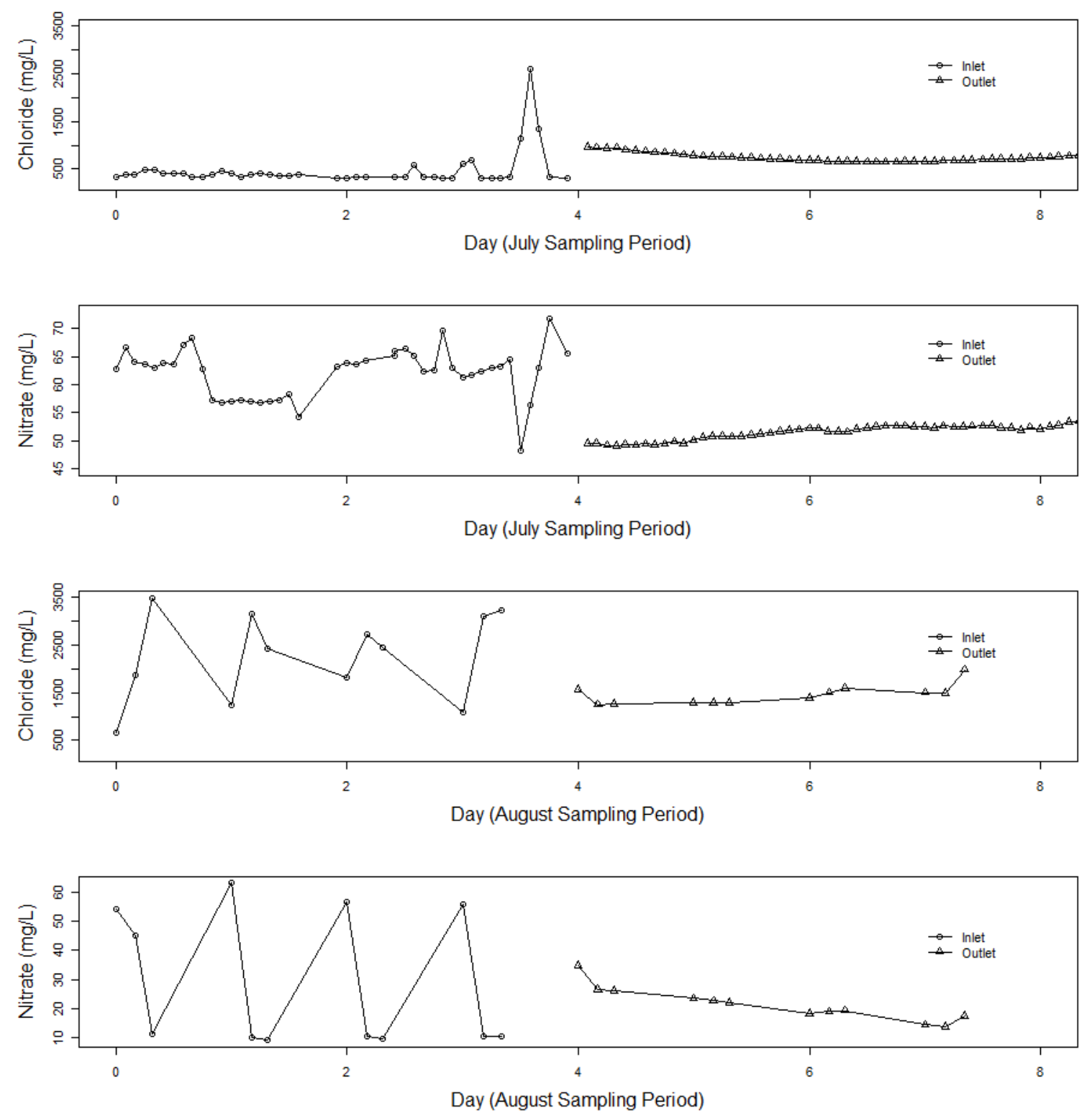
Figure A2: Plots of standardized concentrations of pesticides and other analytes during July and August sampling periods at the inlet show the relationship between salinity (as indicated by Chloride) in the Tembladero Slough and fresh water. When standardized chloride is flat and not changing, the pumped water into the wetland is fresh water, composed predominantly of irrigated runoff or tiledrain water. Chloride spikes represent tidal mixing of saline ocean water in the Tembladero Slough, which is pumped to the inlet. During July inlet sampling of pesticides (through day 2.3) there was flat chloride and therefore good representation of agricultural chemical runoff at the inlet. During August inlet sampling of pesticides, there was considerable variation in chloride, confounding the evaluation and modeling of agricultural chemicals during the August sampling period; as a result, the August data were omitted from the pesticide analysis.

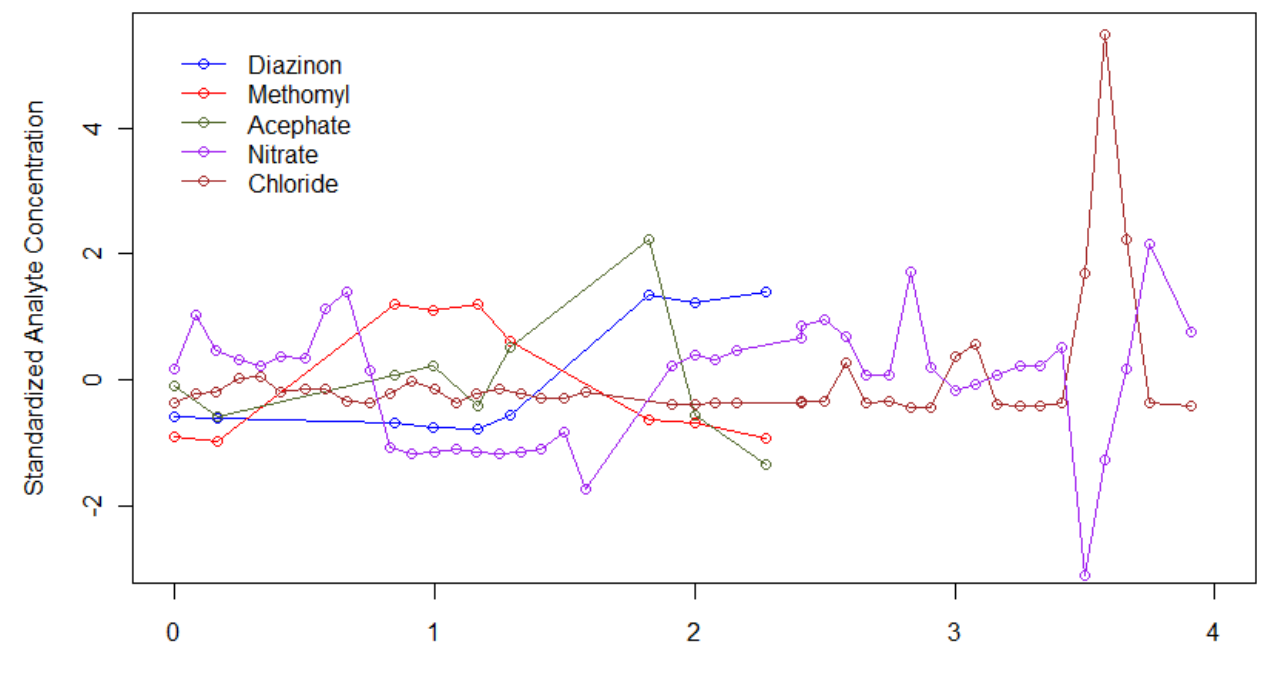

Day (July Sampling)

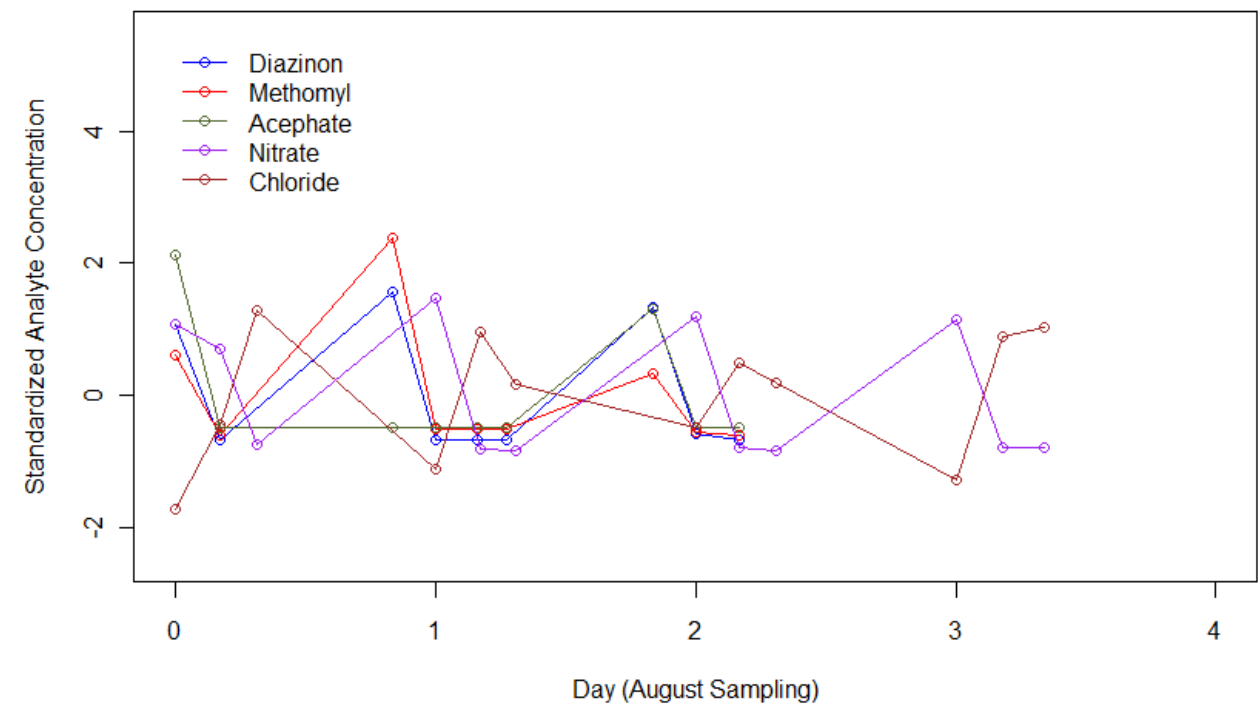




\section{APPENDIX B}

\section{BAYESIAN RESULTS FOR MODEL PARAMETERS}

Table B1. Credible intervals $(95 \% \mathrm{CI})$ and the most probable values from the five MCMC chains are shown for each model parameter.

\begin{tabular}{|c|c|c|c|c|c|}
\hline Pesticide & Parameter & Units & $\begin{array}{l}95 \% \mathrm{CI} \\
\text { low }\end{array}$ & $\begin{array}{l}\text { 95\% CI } \\
\text { high }\end{array}$ & $\begin{array}{c}\text { Most } \\
\text { Probable } \\
\text { Value }\end{array}$ \\
\hline \multirow[t]{6}{*}{ Diazinon } & Decay Rate & day $^{-1}$ & 0.097 & 0.289 & 0.184 \\
\hline & Hydraulic Retention Time & day & 4.11 & 4.51 & 4.32 \\
\hline & Number of Tanks-in-Series & unitless & 15.49 & 17.75 & 16.78 \\
\hline & $\begin{array}{l}\text { Pre-Inlet Sampling } \\
\text { Concentration }\end{array}$ & $\mathrm{ppb}$ & 0.053 & 0.254 & 0.129 \\
\hline & $\begin{array}{l}\text { Post-Inlet Sampling } \\
\text { Concentration }\end{array}$ & $\mathrm{ppb}$ & 0.055 & 0.262 & 0.138 \\
\hline & Standard Deviation & $\mathrm{ppb}$ & 0.005 & 0.013 & 0.005 \\
\hline \multirow[t]{6}{*}{ Methomyl } & Decay Rate & day $^{-1}$ & 0.068 & 0.232 & 0.123 \\
\hline & Hydraulic Retention Time & day & 4.13 & 4.52 & 4.32 \\
\hline & Number of Tanks-in-Series & unitless & 15.55 & 17.90 & 16.62 \\
\hline & $\begin{array}{l}\text { Pre-Inlet Sampling } \\
\text { Concentration }\end{array}$ & $\mathrm{ppb}$ & 0.780 & 4.647 & 1.934 \\
\hline & $\begin{array}{l}\text { Post-Inlet Sampling } \\
\text { Concentration }\end{array}$ & $\mathrm{ppb}$ & 3.769 & 9.365 & 5.529 \\
\hline & Standard Deviation & $\mathrm{ppb}$ & 0.081 & 0.283 & 0.104 \\
\hline \multirow[t]{6}{*}{ Acephate } & Decay Rate & day $^{-1}$ & 0.068 & 0.246 & 0.175 \\
\hline & Hydraulic Retention Time & day & 4.21 & 4.50 & 4.39 \\
\hline & Number of Tanks-in-Series & unitless & 15.88 & 17.97 & 17.05 \\
\hline & $\begin{array}{l}\text { Pre-Inlet Sampling } \\
\text { Concentration }\end{array}$ & $\mathrm{ppb}$ & 0.370 & 2.041 & 1.260 \\
\hline & $\begin{array}{l}\text { Post-Inlet Sampling } \\
\text { Concentration }\end{array}$ & $\mathrm{ppb}$ & 15.353 & 24.999 & 22.269 \\
\hline & Standard Deviation & $\mathrm{ppb}$ & 0.044 & 0.191 & 0.057 \\
\hline
\end{tabular}


Table B2. Five parallel MCMC chains for each pesticide and each week with 20000 runs apiece were compared using the BOA package in $\mathrm{R}$ to ascertain convergence (MPSRF 97.5 percentile < 1.2; Givens et al. 2004). The Brooks-Gelman diagnostic results are shown.

\begin{tabular}{|c|c|c|c|c|c|}
\hline Pesticide & Parameter & Symbol & mpsrf & Estimate & 0.975 \\
\hline \multirow[t]{6}{*}{ Diazinon } & Decay Rate & $k$ & 1.06 & 1.024 & 1.047 \\
\hline & Hydraulic Retention Time & $\bar{\tau}$ & & 1.068 & 1.174 \\
\hline & Number of Tanks-in-Series & $\mathrm{N}$ & & 1.010 & 1.025 \\
\hline & $\begin{array}{l}\text { Pre-Inlet Sampling } \\
\text { Concentration }\end{array}$ & $C_{\text {in,pre }}$ & & 1.009 & 1.023 \\
\hline & $\begin{array}{l}\text { Post-Inlet Sampling } \\
\text { Concentration }\end{array}$ & $C_{\text {in,post }}$ & & 1.017 & 1.036 \\
\hline & Standard Deviation & $\sigma$ & & 1.000 & 1.001 \\
\hline \multirow[t]{6}{*}{ Methomyl } & Decay Rate & $k$ & 1.065 & 1.034 & 1.081 \\
\hline & Hydraulic Retention Time & $\bar{\tau}$ & & 1.002 & 1.006 \\
\hline & Number of Tanks-in-Series & $\mathrm{N}$ & & 1.005 & 1.011 \\
\hline & $\begin{array}{l}\text { Pre-Inlet Sampling } \\
\text { Concentration }\end{array}$ & $C_{\text {in,pre }}$ & & 1.042 & 1.104 \\
\hline & $\begin{array}{l}\text { Post-Inlet Sampling } \\
\text { Concentration }\end{array}$ & $C_{\text {in,post }}$ & & 1.077 & 1.181 \\
\hline & Standard Deviation & $\sigma$ & & 1.011 & 1.026 \\
\hline \multirow[t]{6}{*}{ Acephate } & Decay Rate & $k$ & 1.04 & 1.033 & 1.055 \\
\hline & Hydraulic Retention Time & $\bar{\tau}$ & & 1.009 & 1.020 \\
\hline & Number of Tanks-in-Series & $\mathrm{N}$ & & 1.005 & 1.014 \\
\hline & $\begin{array}{l}\text { Pre-Inlet Sampling } \\
\text { Concentration }\end{array}$ & $C_{\text {in,pre }}$ & & 1.007 & 1.016 \\
\hline & $\begin{array}{l}\text { Post-Inlet Sampling } \\
\text { Concentration }\end{array}$ & $C_{\text {in,post }}$ & & 1.050 & 1.113 \\
\hline & Standard Deviation & $\sigma$ & & 1.007 & 1.016 \\
\hline
\end{tabular}




\section{APPENDIX C \\ TRACER TEST AND DETERMINATION OF PRIORS FOR HYDRAULIC PARAMETERS}

\section{GOAL}

We conducted a tracer test in order to define the number of tanks in series $(\mathrm{N})$ of the upper Molera Experimental Wetland and the mean hydraulic residence time $(\bar{t})$ in terms of a mean and standard deviation for each parameter that could be used as a prior for the Bayesian MCMC analysis of pesticide reduction. A second goal was to determine the target pumping rate during the pesticide experiment.

\section{MeTHODS}

Sodium bromide is used in tracer studies because it does not decay or sorb in wetlands (Kadlec and Knight 1996). We dissolved sodium bromide (15 kg ) into two carboys and released the concentration into the weland inlet stream over a time period of 20 minutes as a bromide spike of 54,200 mg/L (Fig. D.2). The inlet was pumped from the Tembladero Slough into the Molera Experimental Wetland at a discharge rate of 15.5 gpm throughout the tracer test. In order to prevent or minimize sinking of the more dense tracer water near the wetland inlet, we mixed the water close to the inlet using a propeller for 15 minutes subsequent to the addition of the tracer.

An ISCO automatic sampler was placed at the wetland outlet and programmed to collect 0.5 liters of water on an hourly basis. The samples were collected daily for a period of 7 days and taken to the CSUMB lab for analysis. Chemical analysis was done on a Dionex Ion Chromatograph using a modified method EPA 300.0. Quality assurance procedures to insure the accuracy and precision of the data were conducted in accord with normal CSUMB lab protocol (QAPP). These procedures included the calibration of the chromatograph at the start of each run using 6 standards with known concentrations of 0.75, 1.50, 3.50, 7.50 and $15 \mathrm{mg} / \mathrm{L}$ Bromide. Lab duplicates were analyzed and compared to insure that relative percent difference (RPD) was less than $20 \%$. Laboratory and field 
blank samples containing DI water were run and compared with the method detection limit to insure there was no contamination of samples. Laboratory control samples of known concentrations of bromide solution procured from an outside lab were run at the start and end of each run and after every 20 samples to demonstrate the accuracy of the analytical method. At least one matrix spike was run per batch to demonstrate the performance of the analytical method in a sample matrix. Recoveries of $80 \%$ to $120 \%$ were considered to represent acceptable performance for matrix spikes and laboratory control samples.
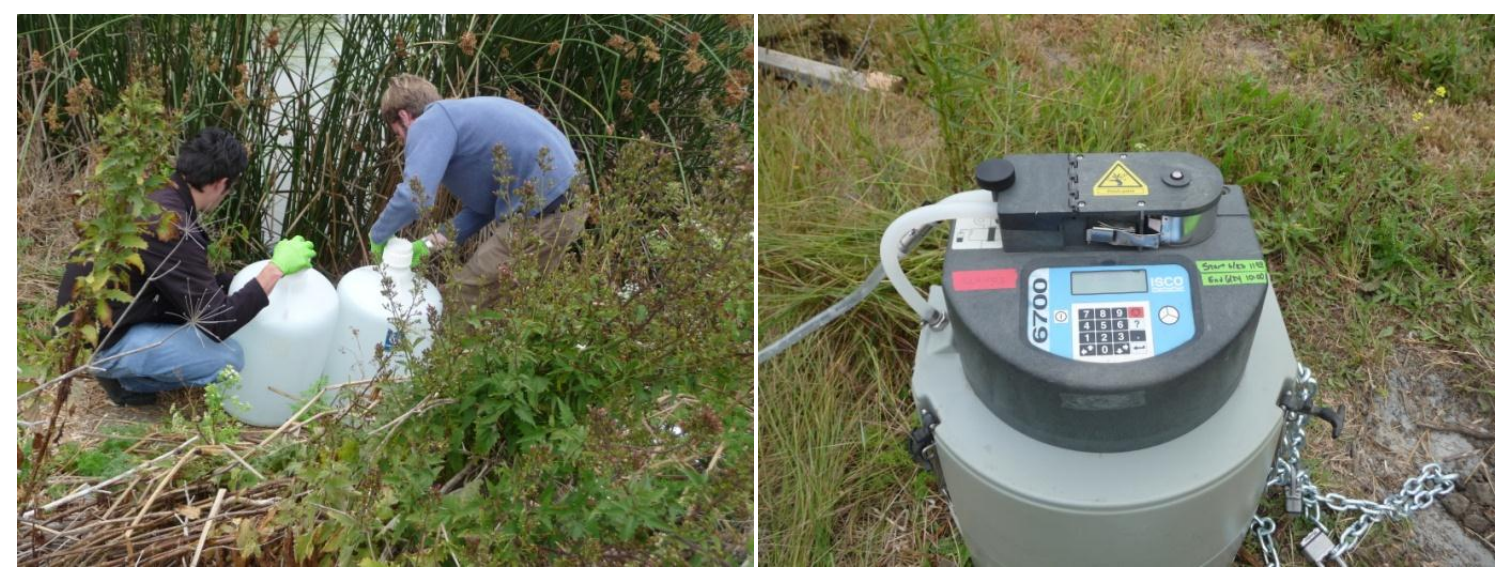

Figure C1. Bromide tracer solution was added over a 20 minute interval at the wetland inlet (left photo). Automated sampling at the outlet using an ISCO 6700 occurred hourly for 7 days (right photo).

\section{Statistical Methods:}

The R Statistical Package was used to implement the DTIS model and a Monte Carlo Markov Chain (MCMC) of 20,000 runs. The joint posterior distribution of the two parameters was estimated using Metropolis sampling (Metropolis et al. 1953, Albert 2009). Inference regarding $\mathrm{N}$ and $\bar{t}$ parameters was derived directly from the posterior PDFs, which were based on likelihood profiles developed by comparing model predictions with outputs from simulations. We determined the most likely value identified by the MCMC run for $\mathrm{N}$ and $\mathrm{t}$ and utilized these values as the mean for the priors in the pesticide MCMC runs. We used a factor (1.5 times) of the standard deviation determined from the distribution as the prior for the NTIS and HRT standard deviation for the pesticide MCMC runs. 


\section{Determining Pumping Rate for Pesticide Sampling}

The value derived for $\mathrm{N}$ could be used directly as the parameter in the pesticide DTIS model; however the desired pumping rate for the pesticide sampling period was determined from the tracer test results. We determined the pumping rate during pesticide sampling in order to have the highest concentration similarity at the outlet as compared with the inlet at 4 days. The desired the pumping rate for the pesticide sampling period in order to achieve the desired peak at 4 days by the equations

$$
t_{2 p}=t_{1 p} \frac{\bar{t}_{2}}{\bar{t}_{1}} \text { and } Q_{2}=\frac{Q_{1} \bar{t}_{1}}{\bar{t}_{2}}
$$

where $Q_{1}\left(\mathrm{~m}^{3} /\right.$ day), $\bar{t}_{1}$ (day) and $t_{1 p}$ (day) respectively represent the discharge, the mean hydraulic detention time and the peak hydraulic detention time during the tracer test and $Q_{2}\left(\mathrm{~m}^{3} / \mathrm{day}\right)$ and $\bar{t}_{2}$ (day) and $t_{2 p}$ (day) represent these variables during the pesticide sampling period.

\section{RESULTS}

The results of the most likely values from the MCMC chain are plotted in Figure C2 as compared with observed sample concentrations of bromide. In hind sight, we should have continued the outlet sampling for a longer time period in order to capture the tail of the tracer test and determine the mass balance, however the shorter than ideal sampling time is unlikely to have influenced our determination of $\mathrm{N}$ and $\bar{t}$ substantially as the peak concentration was well captured. The most likely values for the number of tanks in series was $\mathrm{N}=16.7$ and for the mean hydraulic residence time was ( $\bar{t}=5.67$ days).

Although the hydrology predicted by the model and the observations appear (subjectively) not to coincide as well as desired, any small discrepancies will be corrected by the Bayesian approach we are using.

The high $\mathrm{N}$ for the upper MEW was consistent with the design intent of the wetland. Whereas the mean wetland $\mathrm{N}$ for the 30 wetlands reviewed by Kadlec (2005) was 4.5, for upper MEW the $\mathrm{N}$ was 16.7. Wetlands with an unusually high hydraulic efficiency $(\mathrm{N}>20)$ have occasionally been reported, usually in research facilities or trenches (Kadlec and Wallace 2009). Upper MEW hydrology is closer to plug flow than 
is typical of most wetlands. The difference in the residence time distribution between upper MEW and a wetland with $\mathrm{N}$ of 4.5 is shown in Figure C3.

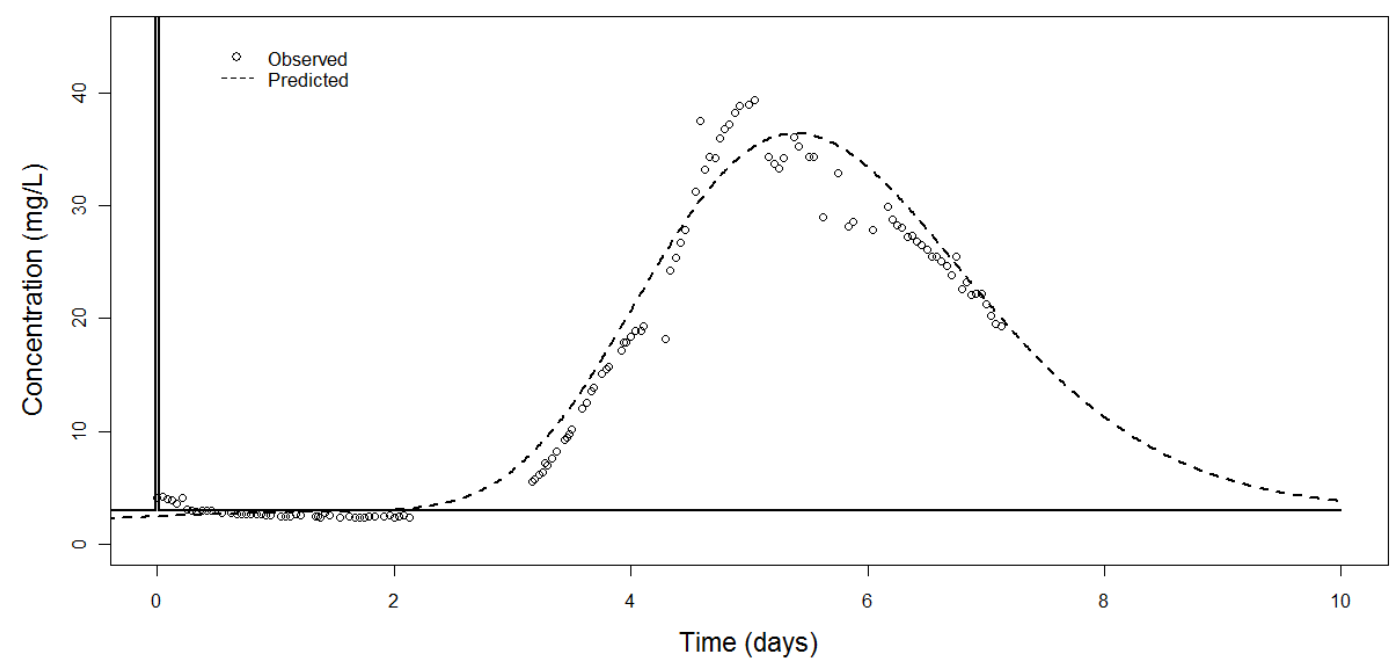

Figure C2. The results of the tracer test showing the most likely model predictions given number of tanks in series $(\mathrm{N})$ of $\mathbf{1 6 . 7}$ and mean hydraulic residence time $(\bar{t})$ of 5.7 days compared with the observed bromide concentrations exiting the wetland. The spike at 0 days represents the tracer addition at the inlet.

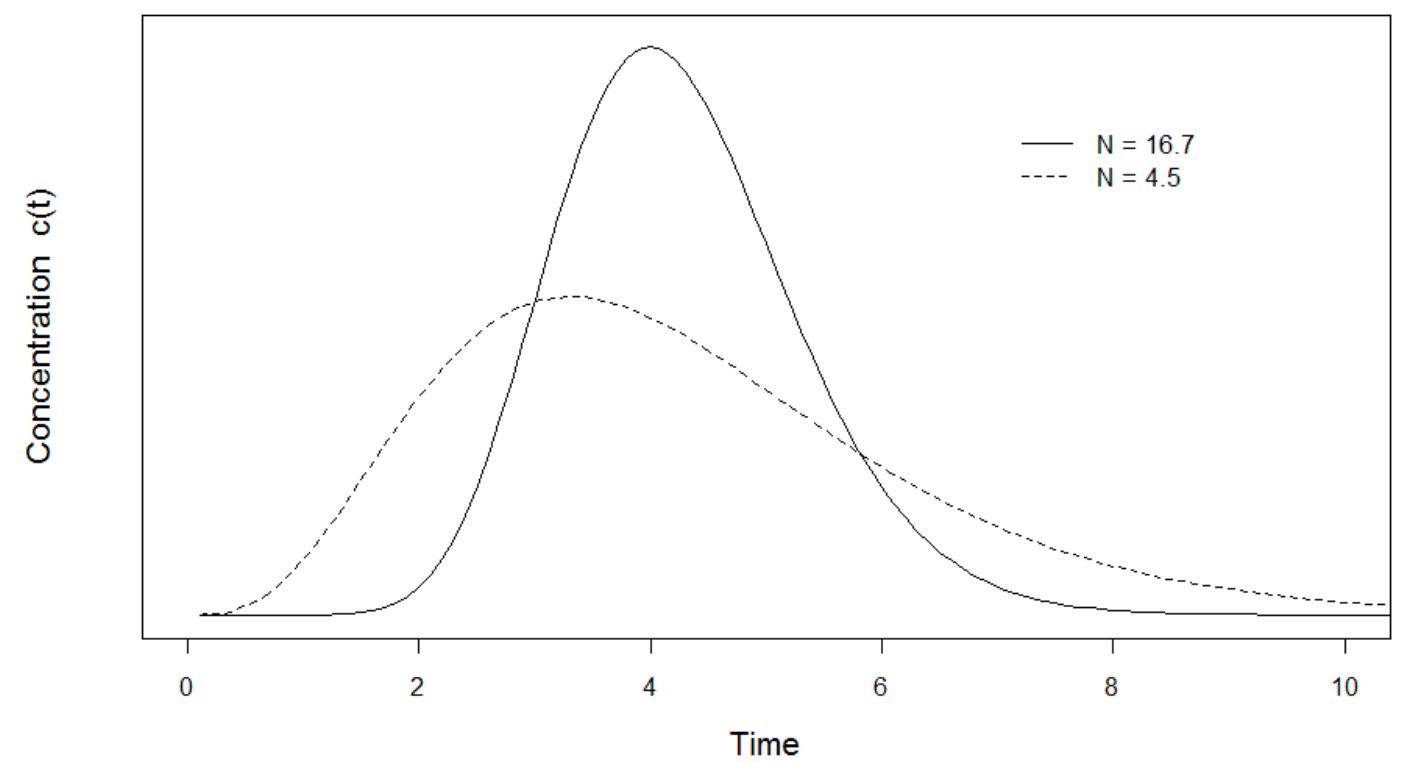

Figure C3. The upper MEW has a most likely $\mathbf{N}$ of 16.7 days such that its hydrology is closer to plug flow than typical wetlands. Kadlec (2005) reported a mean $\mathbf{N}$ for 30 wetlands of 4.5 days. Because of its hydrology, comparisons of inlet and outlet concentrations are better matched at Molera than in most wetlands. 
Based on mean hydraulic detention time ( $\bar{t}_{1}=5.74$ days), the time of concentration peak occurred at 5.4 days. The sampling schedule of the pesticide experiment was 4 days between inlet and outlet sampling, thus the peak concentration is desired at 4 days. The mean $t$ for the pesticide experiment was computed to be 4.25 days in order to achieve the matching inlet - outlet peak at 4 days. Based on a pumping rate of $15.5 \mathrm{gpm}$ during the tracer test, the targeted discharge during the pesticide experiment was $21 \mathrm{gpm}$.

\section{Conclusion:}

We accomplished our goal of determining the most likely value for the number of tanks in series (N) and the targeted mean hydraulic detention time for the upper MEW during the pesticide experiment. The most likely value served as the mean of a normal distribution for these two hydrologic parameters during Bayesian sampling of parameter space. The prior for the number of tanks in series was the mean of $\mathrm{N}=16.7$ and 1.5 times the standard deviation from the MCMC chain results from the tracer test (for an $\mathrm{SD}=0.6)$. The target pumping rate for the pesticide experiment was determined as 21 gpm to achieve a maximum concentration match between outlet and inlet at 4 days time and a mean HRT of 4.25. The prior for mean hydraulic detention time was based on the actual pumping rate during each pesticide experiment. Extrapolation of the mean HRT for each week of pesticide sampling was based on the comparison of actual pumping rates with those during the tracer test and the most likely value of the mean detention time from the tracer test. The mean HRTs were determined for the pesticide experiment during Week 1 as 4.32 days and during Week 2 as 4.26 days. These HRT means and the standard deviation of 0.1 were used for the priors for Metropolis sampling when analyzing the pesticide results. 


\section{APPENDIX D \\ REGULATORY BACKGROUND}

On May 5, 2011 the Central Coast Regional Water Quality Control Board (CCRWQCB) approved water quality goals for a four day continuous concentration average of diazinon and for a 1 hour acute concentration at $0.10 \mathrm{ppb}$ and $0.16 \mathrm{ppb}$ respectively as a total maximum daily load for the lower Salinas River watershed (CCRWQCB 2011). The final report characterizes diazinon as a serious water quality problem affecting multiple beneficial uses and requires the Agricultural Order to include general monitoring at the subwatershed level and individual farm operation monitoring for those discharging to impaired waterbodies (CCRWQCB 2011). Growers will need information on the size and effectiveness of wetland or VTS treatment to make informed business decisions regarding different feasible alternative management practices that may be effective for diazinon removal and other regulated farm chemicals used in their operations.

Neither acephate nor methomyl are included in current TMDLs for impaired water bodies on California's Central Coast, although toxicity data is provided by the US EPA for these chemicals. Acephate toxicity to the water flea (Daphnia magna) has a reported $\mathrm{LC}_{50}$ of 1.62 ppm over a 48 hour period whereas its breakdown product, methamidophos, is toxic at lower concentrations of $0.026 \mathrm{ppm}$ (Paterson 2004). Inlet and outlet samples were considerably lower than the $\mathrm{LC}_{50}$ for acephate. The breakdown product of acephate, methamidophos, was analyzed but not detected in any samples. Methomyl toxicity to the water flea (Daphnia magna) has a reported 48 hour $\mathrm{LC}_{50}$ of 5.0 ppb and a No Observed Adverse Effect Concentration (NOAEC) over a 21 day period of $0.7 \mathrm{ppb}$ based on delayed reproductivity (EPA 2010). 


\section{APPENDIX E \\ TANKS IN SERIES CONCEPTUAL MATH}

A standard tanks in series (TIS) model is an analytic formulation that assumes flow through a wetland behaves in the same way as flow through a series of fully mixed tanks (Clark 2009). This leads to a gamma distribution of residence times based on two parameters, the flow rate and the number of tanks in series (N). The TIS model can be mathematically coupled with equations for the instantaneous rate of chemical decay to lead to a corresponding steady state prediction of the net decay through an entire wetland (Kadlec and Wallace 2009). The hydrology of wetlands has been well-documented to have residence time distribution (RTD) similar to a tanks in series reactor (Kadlec and Knight 1996). Thus the model can be used for wetland design under steady state conditions.

A tanks in series approach can also be used to model dynamic conditions by using a time step modelling approach. A parcel of water entering the wetland, rather than exiting as a pulse, instead exits the wetland over a time period defined by the RTD, which has the shape of a gamma function (Clark 2009). A parcel of water entering the wetland during a single time step, exits the wetland over a number of time steps in partial amounts defined by the RTD gamma function. The water exiting the wetland over the series of time steps as fractional parts is equal to the amount of water entering at the single earlier time step such that their fractional contributions sum to one, thus conserving mass (Clark 2009). Note that we are assuming no loss to ground water or evapo-transpiration and no addition from precipitation. Therefore by normalizing each exiting partial amount of water at a time step over the total amount exiting over all time steps, the fractional portion of entry water is represented (Figure E1). Because the RTD represents the duration of treatment that fractional component of water has undergone and because concentration reduction is time dependent, each exiting fraction will have a reduced concentration of pollutant predicted by the treatment time as defined by the RTD.

The residence time distribution (RTD) follows a gamma distribution: 


$$
\begin{gathered}
g\left(\tau ; k_{R}, \theta_{R}\right)=\operatorname{Gamma}\left(\tau ; k_{R}, \theta_{R}\right)=\frac{N}{\bar{\tau}\lceil(N)}\left(\frac{N \tau}{\bar{\tau}}\right)^{N-1} \exp \left(-\frac{N \tau}{\bar{\tau}}\right), \quad k_{R}=N, \\
\theta_{R}=\frac{\bar{\tau}}{N}
\end{gathered}
$$

where $\operatorname{Gamma}\left(\tau ; k_{R}, \theta_{R}\right)$ is a gamma distribution of residence times $\tau$ with parameters $k_{R}$ and $\theta_{R}, \Gamma(\mathrm{N})$ is a gamma function of $N, N$ is the number or tanks (unitless), $\tau$ is the residence time (hr), $\bar{\tau}$ is the mean residence time (hr) (Nauman and Buffham 1983, Levenspiel 1995, Clark 2009, Kadlec and Wallace 2009).

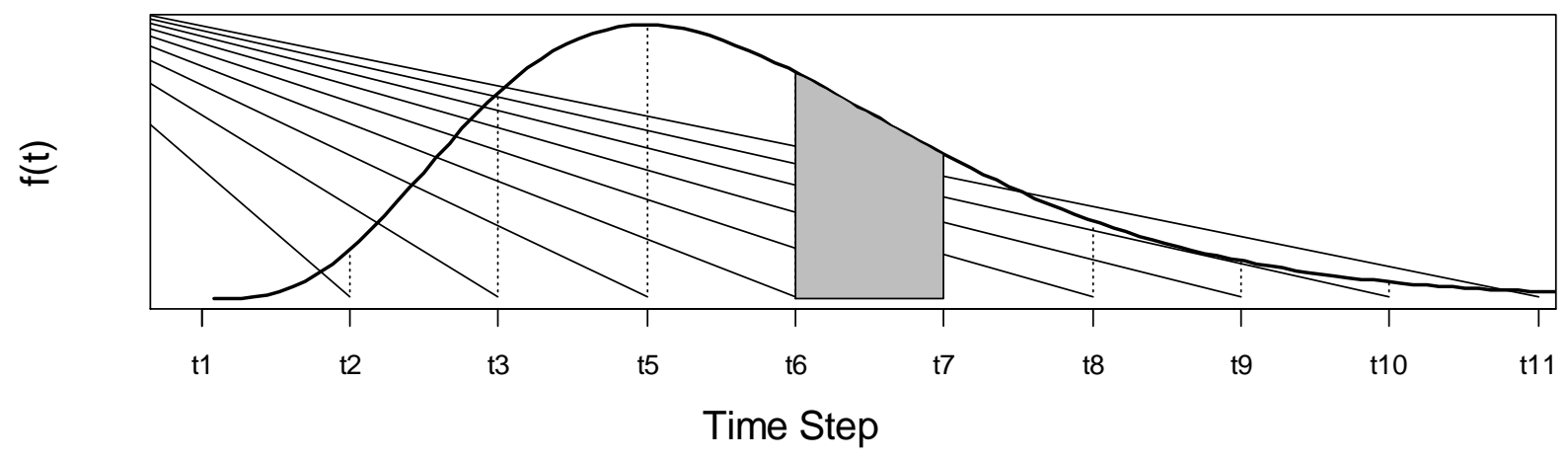

Figure E1: The RTD of tanks in series is a gamma function. This RTD can be divided into a series of time steps and can be used to compute the fractional portion of water exiting the wetland at each step from entry water arriving between to and t1. The gray polygon shows the fraction of water exiting the wetland during a time step from 16 to $t 7$. All the fractions of water exiting the wetland at different time steps sum to 1.

Continuous inlet concentration can be modeled as a series of separate pulses, entering the wetland at time steps (Fig. E2). Each of these inlet pulses is distributed to the outlet in accord with the RTD, thus multiple inlet pulses are arriving at the outlet at the same time (Figure 3). The concentration of each of these pulses can be summed to represent the total concentration exiting the wetland during any time step. Because we are interested in the concentration exiting the wetland at a specific time, when the outlet sample was taken, the various inlet concentrations that contribute to this outlet sample can all be modeled in accord with the RTD, the partial contributions can be summed, and the model can predict the outlet concentration. 
In order to model outlet concentration, it is first necessary to model inlet concentrations. We assumed a linear relationship between measured samples and modeled each time step of inlet concentration based on this assumption.

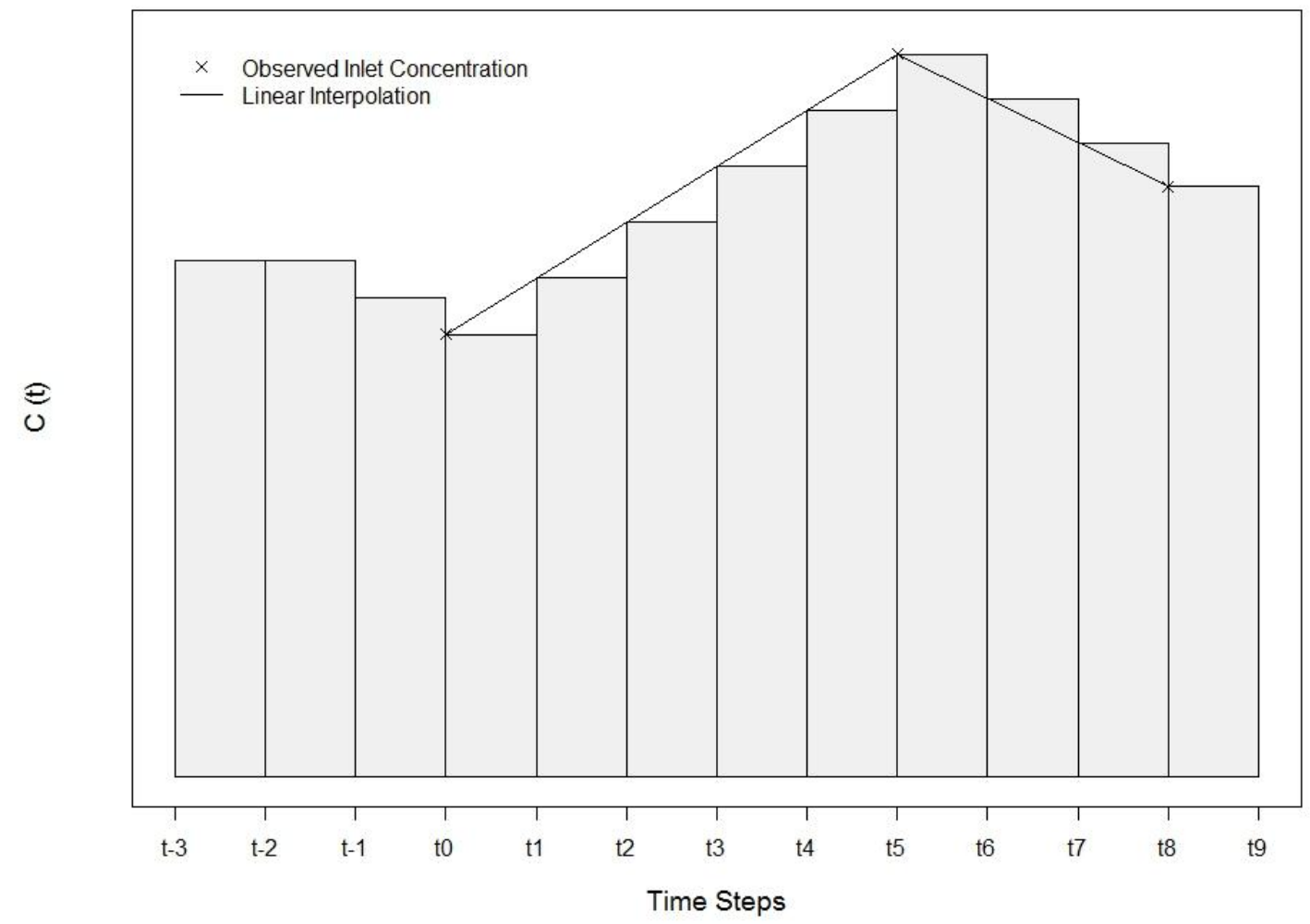

Figure E2. Continuous concentration at the inlet is modeled as a series of concentration pulses, each entering the wetland at a time step based on liner interpolation between measured sample concentrations. Inlet concentrations entering the wetland prior to the inception of sampling must be modeled because they effect outlet sample concentrations.

Outlet concentration is a summary of the partial contributions from concentrations entering at each prior time step (Fig. E3). Measured outlet concentrations taken at known times are compared with model predictions to calibrate the model decay rate. 

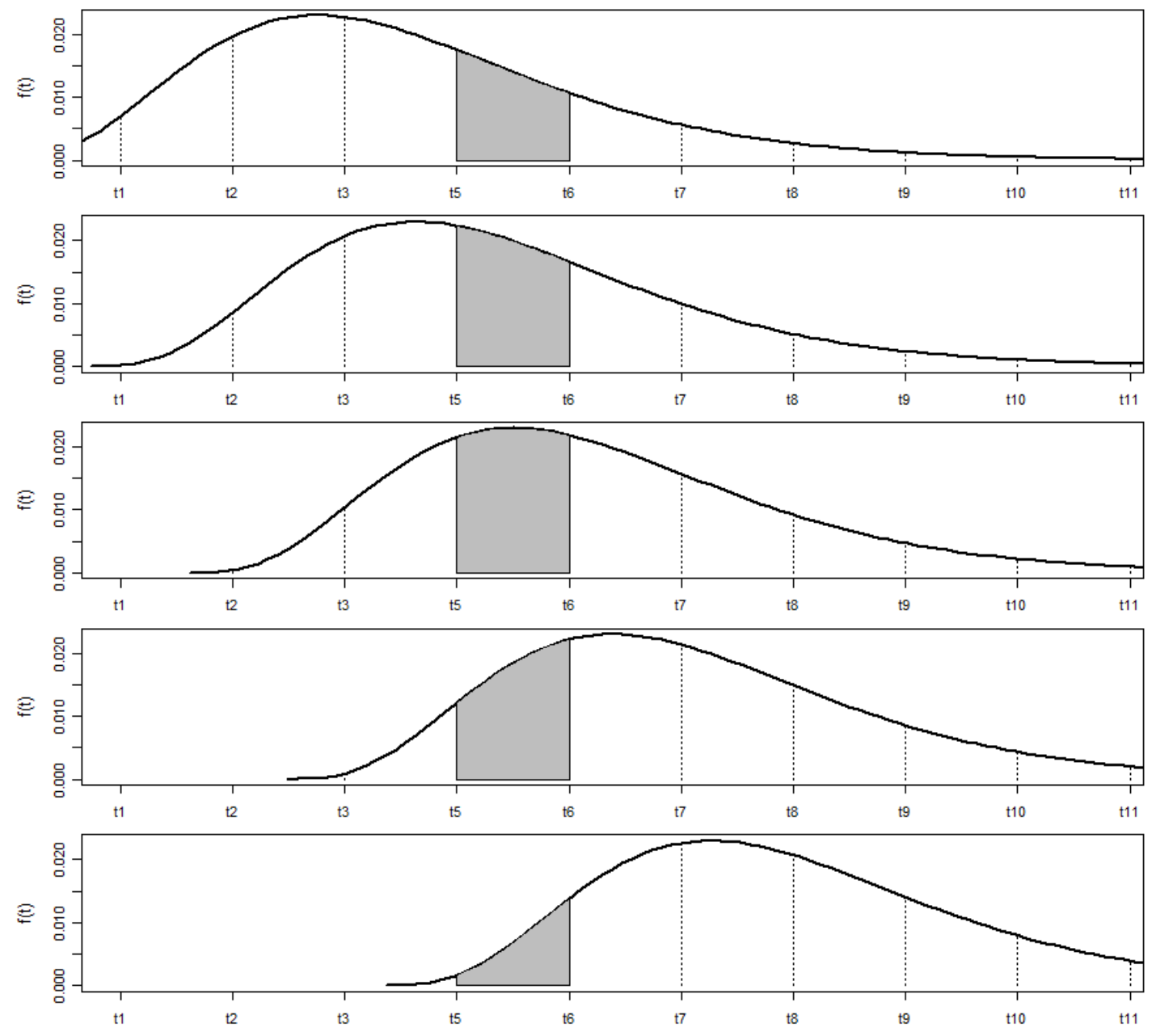

Figure E3: At each time interval a concentration entering the wetland is distributed according to the wetland's RTD to the outlet. From top to bottom, each plot shows how water entering the inlet at progressive time steps is distributed by the RTD to exit at timestep 15 to t6. For the purpose of plot simplicity, time steps are shown as much larger than actually modeled and not all plots are displayed that sum to the exiting portion at 15 to 6 . The middle figure shows water exiting at the time step t5 to t6 that entered the wetland at the interval between inlet and outlet sampling (4days), when the largest fractional inlet portion of water contributes to the outlet concentration. Outlet water concentration exiting the wetland at time step 55 to t6 is the addition of all the partial contributions of water

Degradation of the pesticides investigated was assumed to follow a first order irreversible reaction. Pesticides can be degraded or retained in wetlands by photolysis, volatilization, plant metabolism, sedimentation, hydrolysis, sorption and microbial breakdown (Moore et al. 2008, Kadlec and Wallace 2009). Many of these processes are 
first order reactions, with the exception of photolysis which depends on the depth of light penetration, and microbial breakdown, which typically follows a saturation monad (Kadlec and Wallace 2009). The saturation monad involves a first order reaction for concentrations far below a saturation limit and zero order reactions far above that limit due to the limited ability of the microbial community to respond to dynamics in chemical availability (Kadlec and Wallace 2009). A weakness of the TIS model is that it could not model monad reduction as concentrations are not summed until the final time step, however it could be programmed to model zero order reactions.

The equation for a first order reaction is

$$
C_{o}=C_{i} \exp (-k t)
$$

where $\mathrm{k}$ (-day) is a volumetric rate constant. Due to wetland hydrology and varying residence times of different water parcels, the progress of the reaction must be considered in the context of the RTD function of the wetland, which is mathematically described by (Clark 2009):

$$
C_{o}=C_{i} \int_{0}^{\infty} \exp (-k t) f(t) d t
$$

This concentration curve after degradation also has the shape of a gamma function, however the total area under the curve, as well as the area for each time step, is less by a factor of exp(-kt) (Fig. E4). The curve is also shifted forward due to the exponential decay associated with first order removal. If the removal were assumed to be zero order, there would be no forward shift.

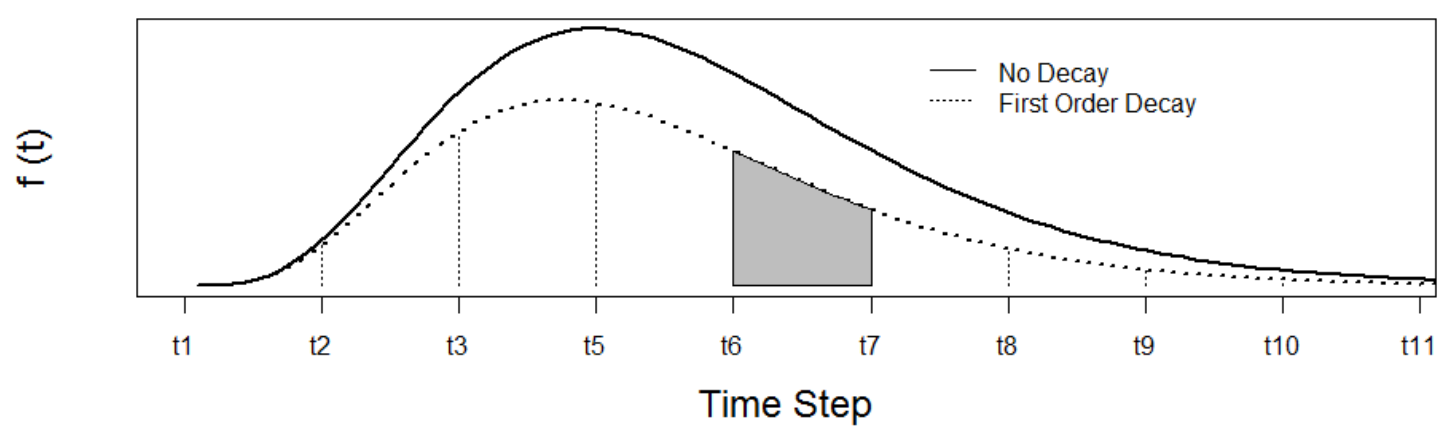

Figure E4: Outlet concentration of a pulse of inlet water containing a known concentration of a degradable chemical can be predicted in accord with principles of decay and wetland treatment time. 
Mathematically, the dynamic TIS model represents dynamic inlet concentrations numerically using a discrete approximation to the integral. Inlet concentration $C_{\mathrm{in}, t}$ varies with actual time $t$ such that the outlet concentration at time $t=T$ results from a mixture of water with a range of residence times and a different inlet concentration associated with each residence time. For first-order decay, where the decay of each parcel is independent of variation in concentration due to mixing with other parcels, the output concentration is the integral over all previous times of the product of the corresponding inlet concentrations, residence time probability densities, and decay function values:

$$
\begin{gathered}
C_{\text {out }, T}=\int_{-\infty}^{T} C_{\mathrm{in}, t} g(T-t) f(T-t) d t \\
C_{\mathrm{out}, T}=\int_{0}^{\infty} C_{\mathrm{in}, T-t} g(t) f(t) d t
\end{gathered}
$$

which we approximated discretely as:

$$
C_{\mathrm{out}, T} \cong \sum_{i=0}^{i_{\max }} C_{\mathrm{in}, T-i \times \Delta t} g^{*}(i \times \Delta t) f(i \times \Delta t)
$$

where the function $g^{*}$ is the residence time distribution function $g$ normalized to unit sum over a discrete number of values separated by a time step $\Delta \underline{t}$, and $i_{\max }$ was set large enough to include effectively all inlet contributions affecting $C_{\text {out }, T \text {. }}$ 